\title{
United in Our Differences: Changing the Face of MSE
}

\section{Lynne Robinson}
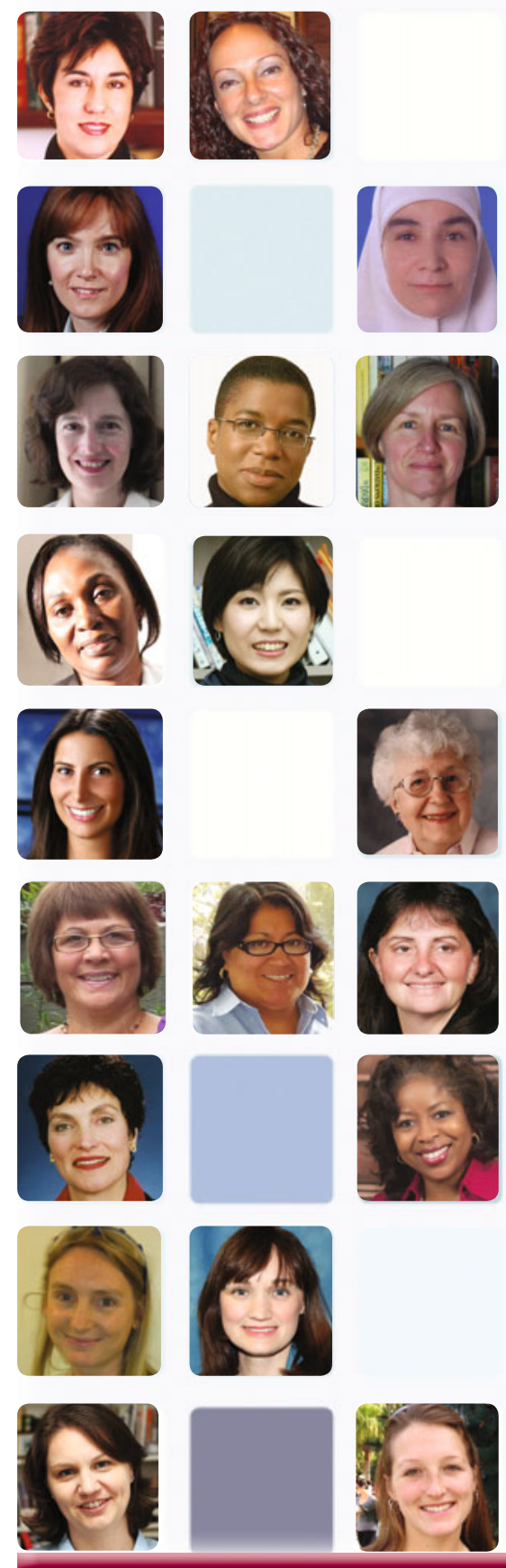

The beauty of a mosaic emerges from the interconnection of its individual pieces, all notably different in shape, luster, and hue, bound together in a common artistic vision. This concept also defines materials science and engineering (MSE) which, by

virtue of its multidisciplinary nature, relies on the unique perspectives of each of its members to make a bold impact.

As with every other field in science and engineering, much effort has been expended in the last few decades on increasing the number of individuals pursuing careers in MSE to ensure that future workforce demands can be met. Although representing half the potential pool

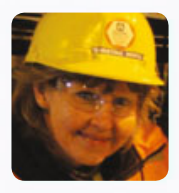
of professionals, women are still a distinct minority in these ranks, with ongoing debate and study as to how to better recruit and retain them. In the meantime, the women who have chosen to call MSE their professional home are making decided changes on the inside, expanding the discussion beyond "women's issues"
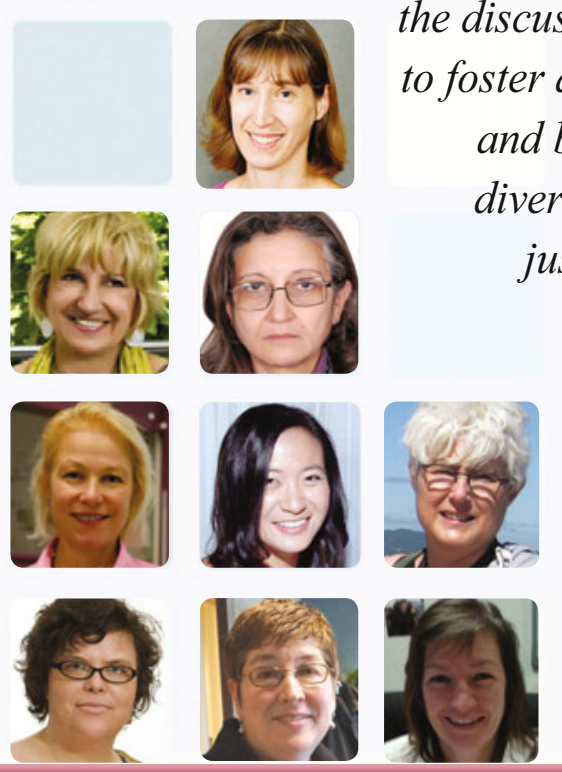
to foster a workplace culture that values and benefits from every definition of diversity. The following pages share just a few of these stories, as told by some truly inspiring TMS members, while also offering perspectives on how MSE can continue to incorporate the many different pieces it needs to create a stronger, more vibrant whole. 


\section{Keith Bowman believes the conversation needs}

\section{to change on the issue of recruiting and}

\section{retaining women and other under-represented}

\section{groups in MSE. And, he would start with the}

\section{commonly used metaphor, "pipeline."}

"It's an inaccurate and negative term," said Bowman, Department Chair and Duchossois Leadership Professor of Materials Engineering, Illinois Institute of Technology. "In reality, if you force people from under-represented groups to go through a "pipeline," they will never get to their destination. There is only one way to enter and one place to go-Pipelines don't tolerate anything leaking in or out in different directions."

Bowman prefers "pathway," particularly when describing MSE. "Even at the undergraduate level, people come to MSE from many areas, and at different points in their educational and professional development. That is something that is very distinct about MSE when compared with other fields," he said. "Pathway reflects that we are open to a variety of experiences, interests, and ideas-We are not locked into one 'right way' to succeed in this field."

The interdisciplinary nature of MSE, noted Bowman, is one characteristic that would seem to make the field ideal for the development of a truly diverse professional community. In papers that he has recently published on the topic, Bowman discusses other factors such as the "relative youth of the MSE discipline," and a research group culture that is "relatively informal and less hierarchical, allowing individuals more flexibility in a way that echoed cultural concepts tied to postmodernist views of plurality and creativity,"' as explored in current social science scholarship. ${ }^{2}$ The small size of the field, he notes, also allows for more individualized, supportive interactions.

Through an exhaustive analysis of demographic data compiled by the American Society for Engineering Education (ASEE), Bowman has determined that MSE has made some footholds in living up to its promise as an inclusive profession. In terms of female representation in faculty positions in the United States, MSE fares little better than average than engineering as a whole for total faculty positions. However, MSE outpaced other engineering disciplines at the full professor rank in the first decade of this century-increasing the fraction of female MSE professors from $6 \%$ to $11 \%$, compared with a $5 \%$ to $8 \%$ increase in engineering overall. ${ }^{1}$ During the same time period between 2000 and 2009, the number of women awarded Ph.D.s in MSE nearly doubled. In 2009 , the final year of the decade studied, women represented $24 \%$ of total MSE Ph.D.s earned that year. This outperformed the percentage of Ph.D.s granted to women in engineering in total, which increased from $16 \%$ in 2000 to $21 \%$ in 2009 . $^{1}$
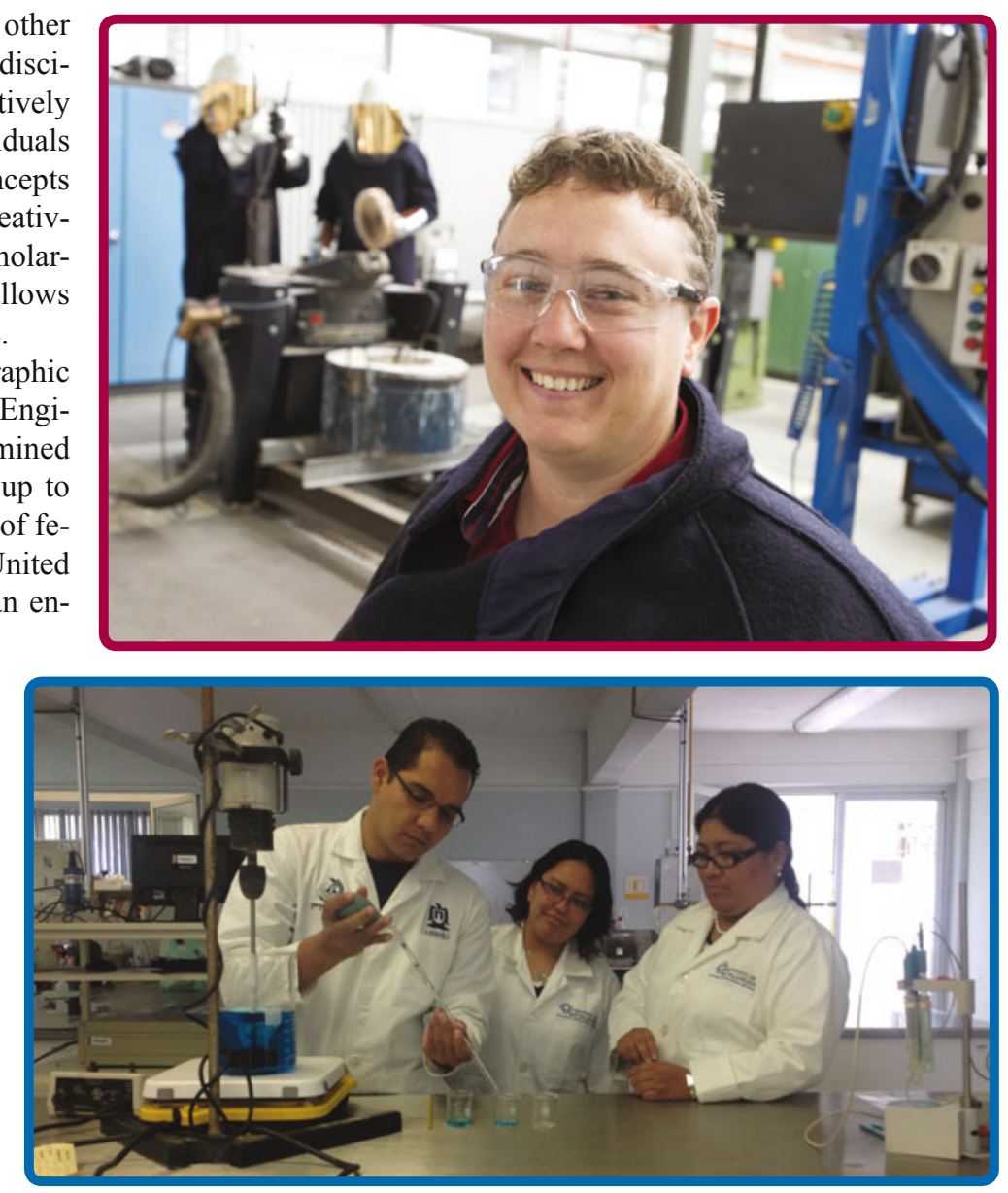
While these are positive signs, Bowman says that more current data indicate that forward progress in creating an MSE professional community that is as varied as the many disciplines feeding into it could be approaching a plateau. In examining ASEE statistics from 2011 - the most current available at press time-Bowman notes that the growth in awarding Ph.D.s to women has slowed significantly within the last five years, with a notable dip in the percentage of total MSE Ph.Ds (Table I). The growth in the percentage of tenured female faculty has likewise remained flat (Table II). The influx of other under-represented groups has also either experienced little to no im-

\begin{tabular}{|c|c|c|c|c|c|c|c|c|c|c|c|c|}
\hline & Total $^{*}$ & $\begin{array}{c}\text { African } \\
\text { Amer. }\end{array}$ & $\begin{array}{l}\text { Asian } \\
\text { Amer. }\end{array}$ & $\begin{array}{l}\text { Hispanic } \\
\text { Amer. }\end{array}$ & $\begin{array}{l}\text { Native } \\
\text { Amer. }\end{array}$ & $\begin{array}{l}\text { Pacific } \\
\text { Isle } \\
\end{array}$ & Caucasian & Internat'I & $\begin{array}{l}\text { Two or } \\
\text { More }\end{array}$ & $\begin{array}{c}\text { Otherl } \\
\text { Unknown } \\
\end{array}$ & Male & Female \\
\hline \multicolumn{13}{|l|}{ Number } \\
\hline 2007 & 584 & 4 & 38 & 3 & 0 & 0 & 169 & 338 & 0 & 32 & 427 & 157 \\
\hline 2011 & 623 & 6 & 40 & 10 & 2 & 0 & 167 & 345 & 5 & 48 & 474 & 149 \\
\hline Change & 39 & 2 & 2 & 7 & 2 & 0 & -2 & 7 & 5 & 16 & 47 & -8 \\
\hline \multicolumn{13}{|l|}{ Percent } \\
\hline 2007 & 584 & $1.6 \%$ & $15.4 \%$ & $1.2 \%$ & $0.0 \%$ & $0.0 \%$ & $68.7 \%$ & $57.9 \%$ & $0.0 \%$ & $5.5 \%$ & $73.1 \%$ & $26.9 \%$ \\
\hline 2011 & 623 & $2.2 \%$ & $14.4 \%$ & $3.6 \%$ & $0.7 \%$ & $0.0 \%$ & $60.1 \%$ & $55.4 \%$ & $0.8 \%$ & $7.7 \%$ & $76.1 \%$ & $23.9 \%$ \\
\hline Change & $6.7 \%$ & $0.6 \%$ & $-1.0 \%$ & $2.4 \%$ & $0.7 \%$ & $0.0 \%$ & $-8.6 \%$ & $-2.5 \%$ & $0.8 \%$ & $2.2 \%$ & $3.0 \%$ & $-3.0 \%$ \\
\hline
\end{tabular}

Data source: ASEE Database

Analysis provided by Keith J. Bowman

U.S. Demographic Diversity Corrected for International Students-Shown in Shaded Cells

Table II. MSE Faculty Demographics in the United States

\begin{tabular}{|c|c|c|c|c|c|c|c|c|c|c|c|}
\hline & $\begin{array}{c}\text { Total } \\
\text { Tenure/ } \\
\text { Tenure } \\
\text { Track } \\
\text { MSE } \\
\text { Faculty }\end{array}$ & Male & Female & $\begin{array}{c}\text { African } \\
\text { Amer. }\end{array}$ & $\begin{array}{l}\text { Asian } \\
\text { Amer. }\end{array}$ & $\begin{array}{c}\text { Hispanic } \\
\text { Amer. }\end{array}$ & $\begin{array}{c}\text { Native } \\
\text { Amer. }\end{array}$ & $\begin{array}{l}\text { Pacific } \\
\text { Isle }\end{array}$ & Caucasian & $\begin{array}{c}\text { Other/ } \\
\text { Unknown }\end{array}$ & $\begin{array}{c}\text { Af- } \\
\text { Amer+Hisp } \\
+ \text { Nat } \\
\text { Amer+Pac. } \\
\text { Isle }\end{array}$ \\
\hline \multicolumn{12}{|l|}{ Number } \\
\hline 2011 & 852 & 730 & 122 & 19 & 187 & 23 & 0 & 4 & 563 & 52 & 46 \\
\hline Change & 63 & 47 & 16 & 6 & 9 & 3 & -1 & 4 & 12 & 26 & 12 \\
\hline \multicolumn{12}{|l|}{ Percent } \\
\hline 2007 & 789 & $86.6 \%$ & $13.4 \%$ & $1.6 \%$ & $22.6 \%$ & $2.5 \%$ & $0.1 \%$ & $0.0 \%$ & $69.8 \%$ & $3.3 \%$ & $4.3 \%$ \\
\hline 2011 & 852 & $85.7 \%$ & $14.3 \%$ & $2.2 \%$ & $21.9 \%$ & $2.7 \%$ & $0.0 \%$ & $0.5 \%$ & $66.1 \%$ & $6.1 \%$ & $5.4 \%$ \\
\hline
\end{tabular}

Data source: ASEE Database

Analysis provided by Keith J. Bowman

\begin{tabular}{|c|c|c|c|c|c|c|c|c|c|c|c|c|}
\hline & Total & $\begin{array}{c}\text { African- } \\
\text { Amer. }\end{array}$ & $\begin{array}{l}\text { Asian- } \\
\text { Amer. }\end{array}$ & $\begin{array}{c}\text { Hispanic } \\
\text { Amer. }\end{array}$ & $\begin{array}{l}\text { Native } \\
\text { Amer. }\end{array}$ & $\begin{array}{l}\text { Pacific } \\
\text { Isle }\end{array}$ & Caucasian & Internat'I & $\begin{array}{c}\text { Two or } \\
\text { More }\end{array}$ & $\begin{array}{c}\text { Otherl } \\
\text { Unknown }\end{array}$ & Male & Female \\
\hline \multicolumn{13}{|l|}{ Number } \\
\hline 2007 & 916 & 21 & 120 & 46 & 2 & 2 & 637 & 49 & 3 & 36 & 653 & 263 \\
\hline 2011 & 1155 & 30 & 141 & 52 & 3 & 2 & 767 & 71 & 9 & 80 & 825 & 330 \\
\hline \multicolumn{13}{|l|}{ Percent } \\
\hline 2007 & 916 & $2.4 \%$ & $13.8 \%$ & $5.3 \%$ & $0.2 \%$ & $0.2 \%$ & $73.5 \%$ & $5.3 \%$ & $0.3 \%$ & $3.9 \%$ & $71.3 \%$ & $28.7 \%$ \\
\hline 2011 & 1155 & $2.8 \%$ & $13.0 \%$ & $4.8 \%$ & $0.3 \%$ & $0.2 \%$ & $70.8 \%$ & $6.1 \%$ & $0.8 \%$ & $6.9 \%$ & $71.4 \%$ & $28.6 \%$ \\
\hline Change & $26.1 \%$ & $0.4 \%$ & $\overline{-0.8 \%}$ & $-0.5 \%$ & $\overline{0.1 \%}$ & $\overline{0.0 \%}$ & $-2.7 \%$ & $\overline{0.8 \%}$ & $\overline{0.5 \%}$ & $3.0 \%$ & $0.1 \%$ & $-0.1 \%$ \\
\hline
\end{tabular}

Data source: ASEE Database

Analysis provided by Keith J. Bowman

U.S. Demographic Diversity Corrected for International Students-Shown in Shaded Cells 
provement in both of these indicators.

The real cause for concern, though may lie in the MSE bachelor degrees statistics. While MSE holds its own among other engineering disciplines in terms of gender diversity for awarding bachelor degrees, ${ }^{3}$ the percentage of total MSE degrees granted to women has not improved, with a similar trend seen for other under-represented groups (Table III).

"Most people will say that the num-

\section{Elizabeth Holm}

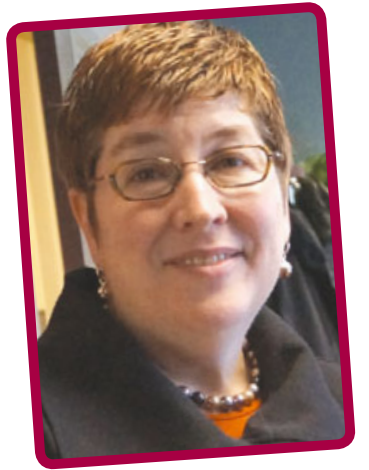

Elizabeth Holm's

\section{journey as a materials}

\section{scientist and engineer}

\section{began with a simple}

\section{question.}

"What do you want to be when you grow up?" her father, a pediatrician, asked.

"I want to be a nurse," said Holm, who was around seven at the time.

"A nurse? Why not a doctor?" her father queried.

"Because girls are nurses, and boys are doctors," Holm replied.

Her father said nothing more, but in a few weeks, her family hosted one of his colleagues for dinner-a female pediatrician who worked at a major hospital in Detroit, Michigan. "Her name was Elizabeth, just like mine," Holm recalls warmly. "At that moment, I realized that I could be a doctor or anything else, and I never questioned that again. The key was seeing it. Until you see an example in person, it is very hard to imagine something entirely new."

Holm said her experience as a young child echoes the results of recent studies examining factors that support women in completing their Ph.D.s in science and engineering.

\section{Professor, Materials \\ Science and \\ Engineering \\ Carnegie Mellon \\ University}

\section{TMS President}

\section{USA}

"What correlates the most with the likelihood of a woman finishing the process is not whether she has a female advisor or support structures available specifically for female students. It's whether or not there is a woman on the department's faculty," said Holm. "You can talk all you want, but it's only when you see that a woman can succeed in your field that you really believe it."

Holm said that she herself never had a mentor who was a woman and, while in school, was never in a department that had a woman on faculty who received tenure. "I have had very excellent male mentors, including and especially my Ph.D. advisor, who was always conscientious about giving me the same opportunities and attention that any of his students received," she said. "These individuals were critical to my self-image as a professional. I knew I had a right to be there, that I was a full member of the community, and I did not need to not be me."

Later in her career, Holm said one of the most "useful things I ever did" was to participate in a gender-based communication workshop when she worked at Sandia National Laboratories. "This not only enlightened me about some aspects of my interactions with male colleagues, but it also freed me," she said. "It helped me realize that I was able to be more direct than would be acceptable if I worked pri-
"While we have

more young women

entering MSE than

in the past, our test

now is to take that

to the next level and

find ways to support

them as they

negotiate those

challenging early

years of their

careers."

marily with other women. This approach fit better with my own personality. That experience helped me let go to be the person that I am naturally with male colleagues, enabling all of us to communicate more effectively."

Adjusting to the norm of a work environment is not solely a genderbased issue, maintains Holm. "All of us have to do less-than-natural things in our jobs-We dress differently, speak more formally, and need to be more considerate than we might be at home. You need to adjust your behavior so that you can be as effective as possible in our position. You limit your options if you don't."

"At the same time, we, as a profession, need to work to change the norms so that they are as inclusive as possible," Holm continued. "That culture shift has started to occur as more women, in particular, have entered the field. But, there is a great deal more that still needs to be done." 
ber of women has gone up, and that is true," said Bowman. He explains that the issue, stems - ironically - from the significant growth MSE has experienced since the turn of the century. The number of bachelor degrees awarded in MSE rose more than 25 percent between 2002 and 2011. ${ }^{3}$ While recruitment efforts have clearly succeeded in increasing the sheer volume of new professionals, the number of women, as a percentage of this volume, has not kept pace.

"To sustain this growth in MSE, we will need more faculty, but how are we going to improve diversity at that level if the diversity numbers at the bachelor's and graduate level flatten out?" Bowman said.

With scientific accomplishments focused on structural and electronic ceramic materials, Bowman has made it a personal mission to challenge the MSE community in embracing its potential of becoming a model of inclusion among engineering disciplines. His scholarship that indicates a potential stalling on the progress that has already been made surprises some, he said, noting, "Like any problem in engineering, you first need to identify something as a problem, and then decide as a group that you want to do

\section{Julia Weertman}

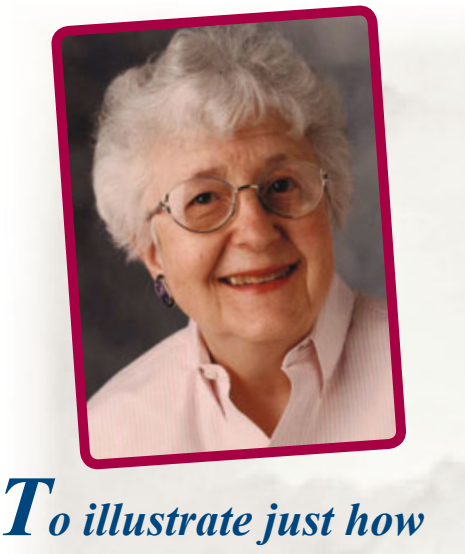

\section{far women have come in science, Julia Weertman \\ refers to the story of}

\section{Maria Goeppert-Mayer,}

\section{the second woman to}

\section{be named a Nobel Prize}

\section{laureate in physics.}

Despite her obvious brilliance, Goeppert-Mayer was hard-pressed to find a permanent, paid appointment as a professor and researcher in the first half of the $20^{\text {th }}$ century. "She was thrilled just to be allowed to sit at a desk in her husband's laboratory at the University of Chicago," quipped Weertman.

Even after reaching the pinnacle of scientific recognition for her work in developing the nuclear shell model of atomic nuclei, Goeppert-Mayer's accomplishment was heralded with the local newspaper headline, "S.D. Moth-

\section{Walter P. Murphy}

Professor Emerita

\section{Northwestern University}

\section{USA}

er Wins Nobel Prize." Weertman, who earned her doctorate in physics in 1951 from the Carnegie Institute of Technology (now Carnegie Mellon University), remembers the double standard that pervaded the media in those days. “Although Dr. Mayer's early struggles were before my time, I recall as a student noticing, with annoyance, that in newspaper articles on scientific achievements, women were always referred to as Miss X-and they were inevitably Miss X-even though they had a Ph.D., while the men were $D r$. Y," she said. "The current attitudes toward women in science and engineering are just part of the enormous changes in attitudes toward many aspects of society."

Weertman notes that she has not really encountered gender discrimination herself during her long career, saying, "I was lucky to be associated with firstrate people all along the way. Such individuals tend to be more generous and not afraid of competition." Her greatest personal challenge was re-entering the scientific workforce after taking 13 years off to stay home with her children. Her husband's ties to academia, as well as her own decision to switch from physics to materials science-as a still-budding discipline, it offered more flexibility-led to an appoint-

\section{"Try always to work with the best people."}

ment as a visiting assistant professor at Northwestern University. Weertman quickly escalated this foothold into one of the most distinguished careers in MSE. Among her many awards and honors, she was named the first female TMS Fellow in 1993.

Weertman believes that juggling professional and personal obligations is still challenging for many who choose science or engineering as a career path, saying, "It would be very helpful if there were more programs to support returning to the work force after a prolonged absence." She also still gives poor marks to popular culture in its presentation of positive female role models. ("How do you find a person who can compete with Beyoncé?")

With women recognized for their scientific accomplishments being few and far between when she was a child, Weertman said she found her inspiration in aviation.

"I was fascinated by the glamor of flying, the continual setting of new records for long and 'fast' flights, and the danger," she said. "This interest started for me around $7^{\text {th }}$ grade, and I chose the science track in school, since that was most appropriate to flying. Later on, thanks to an excellent science teacher, and as reality set in, I switched to physics. I knew I wasn't going to be another Amelia Earhart."

Instead, she went on to become a great materials scientist. 
something about it. Until you do that, it's pretty hard to formulate a solution."

To regain momentum, Bowman maintains that it will be necessary to step beyond the construct of relegating diversity to a special initiative or efforts that serve to redistribute an already existing pool of individuals. "This can't be delegated to a subset of people," he said. "We all have to own it. It needs to be the job of every department chair and faculty member, as well as the job of our professional society leadership and members. How are we all contributing to making this profession welcoming to all people? Unless you can imagine yourself being a materials scientist or engineer, would you really want to do it?"

"Increasing diversity is not just about improving our enrollment numbers," Bowman continued. "We need the full spectrum of people to be part of our discipline. If we don't include segments of the population who have the capacity to do what we do with new ideas, approaches, and other sources of creativity, we lose part of the richness of what is possible. The essence of what we could accomplish may be limited because we don't have a broad vision going into the design of a solution."

\section{INSIGHTS FROM THE MINING INDUSTRY}

Ensuring inclusion of diverse perspectives as a necessary strategy for securing competitive advantage is a point that Clare Beckton, executive director, Centre for Women in Politics

\section{Isabel Lázaro}

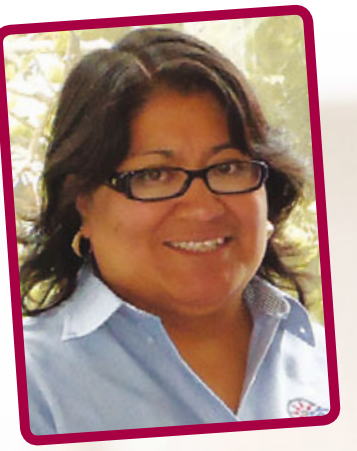

\section{The community that}

\section{binds together scientific}

\section{pursuit has been a huge}

\section{factor in the life and}

career of Isabel Lázaro,

\section{starting with her high}

\section{school chemistry teacher,}

\section{Mrs. Morgado.}

"She encouraged a group of us to enter an experimental chemistry contest that involved preparing salts from copper, silver, and gold," Lázaro recalled. Copper samples were economical enough to acquire, but the precious elements were a different matter. Determined that her students would do well in the contest, "Mrs. Morgado brought some of her own gold and silver jewelry to school and we used it to practice preparing solutions for our

\section{Director, Instituto de} Metalurgia

\section{Universidad Autónoma} de San Luis Potosí

\section{Mexico}

experiments," said Lázaro. "Hopefully, the fact that we won was rewarding of her efforts."

Throughout her career, Lázaro has carried with her the lessons of Mrs. Morgado's generosity, as well the love of chemistry instilled by her early school experiences. ("It looked like a magic trick and from then on I seized any opportunity to be in a laboratory," Lázaro recounts about a cementation of copper experiment that first inspired her in middle school.) Her parents, she said, raised her to appreciate the power and promise of a good education. "My father and mother only reached the elementary school level, but they always encouraged us to aspire to the highest level of education - an opportunity they did not have," she said. Despite economic limitations, Lázaro's parents made sure that she and her siblings attended the best schools possible, even if it meant traveling an hour one-way by bus through Mexico City. All of them, Lázaro notes proudly, have college degrees, and she and her brother hold Ph.Ds.

Interestingly, much of Lázaro's current research focuses on hydrometallurgy and electrochemistry for copper
"Today's rapid

changes in

technology can be

used to awaken the

spirit of scientific

discovery in young

people."

extraction, as yet another link back to her early school influences. "In each stage of my education, there was someone from whom I learned valuable things," she said. A significant turning point in her career was the decision to pursue her doctorate in Australia at Murdoch University, at the encouragement of her master's advisor. "It expanded my vision of research," she said.

Lázaro draws heavily from her experiences to support the community of learners in her own laboratory and classroom. This includes providing flexibility to students with family obligations "to work under timetables that suit them, as well as scholarships to help with expenses." And while she believes that personal conviction is the key to success in any science or engineering career, "I have learned that one cannot work alone, that everything is better as a team, and you should treat people the way you want to be treated." 


\section{"We need to work to the next level where all} differences are erased, where every single class of diversity is welcomed, and no one ever stands out in a negative way because of who you are."

—Elizabeth Holm, 2013 TMS President

and Public Leadership, Carleton University, Canada, stresses in her discussion of a recent study released by her organization on developing gender- inclusive leadership in the Canadian mining industry. "There is mounting evidence that a company's bottom line is higher when there is diversity in senior management and in the board room," she said. "It's to a point that big investment companies are looking at this when making their business decisions."

The mining industry, acknowledged Beckton, does operate under a unique set of challenges to achieving this balance in the ranks of leadership, as well as to recruiting new professionals in general. The isolation of some mining sites and the extensive travel required of top management in global mining companies are among these factors. "Many of our study's findings, however, can apply across science and tech-

\section{Joy H. Forsmark}

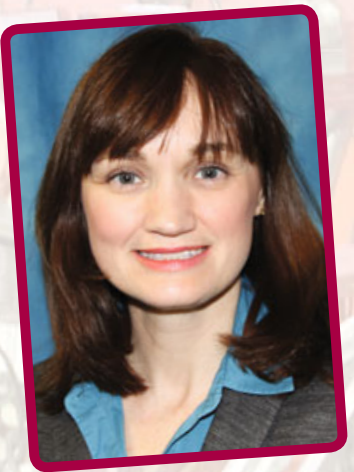

\section{Joy Forsmark learned}

\section{the value of challenging}

\section{"conventional wisdom"}

\section{very early in her career.}

"In graduate school, I was assigned a structural material and told to make a creep map. I started doing the calculations and it wasn't making any sense so I went into the literature to start looking at the diffusion equations I was using," Forsmark said. "I remember I went back five papers to finally find the original one that measured the particular diffusion coefficient I was looking for. It was written in 1933 and was actually in German. It turned out that two numbers had been transposed in the next paper that referenced that work and the mistake stuck! This taught me to always question. If something doesn't look right,
Technical Expert,

Light Cast Metals

Ford Research and

Advanced Engineering

Ford Motor Company

USA

challenge it. This is a lesson I have never forgotten."

Forsmark has carried this approach beyond technical application to advocating for the profession that she loves. "I think there is still a perception that the engineering world is not as welcoming to women as other fields, and I don't feel that this is true," she said. "For me, personally, the challenges I have experienced along my career have not been due to my being female.

"Everyone is going to be tested, whether it is being rejected, working for or with someone difficult, or otherwise just not having something pan out. Sometimes you fight, sometimes you ride it out, sometimes you find a way around, and sometimes you cut your losses and move on."

The mother of an infant son, Forsmark points to her own company as an indicator of how the science and engineering workplace is changing to accommodate work-life balance for

\section{"Materials}

\section{engineering is}

one of the most

rewarding careers

that you can

pursue. I truly feel

like I can be part of

\section{the solution."}

both men and women. "At Ford, we have programs where one can work part-time for a few years, in addition to job sharing, flexible schedules or the ability to telecommute for one to two days a week. I know both women and men who take advantage of these programs and I think this is taking off at a lot of other companies. I'm not promoting any hard and fast rules, but I do think we are seeing a lot more creativity in the work environmentand that benefits everyone."

"I think a lot of women may not consider an engineering career because of concerns that the field is not supportive of female professionals," she continued. "That might have been true in the past, but it is not now. We have to get that message out and then I think we'll create a 'virtuous' cycle of creating more diversity in the profession." 
nology disciplines," she said.

While the nature of the work in mining can't really change, Beckton said there are a number of creative "best practices" that can be further developed to achieve the work-life balance that many potential professionals in the industry seek. This includes introducing flexible work opportunities, rethinking the length of shifts and work days, supporting the provision of childcare services, and better utilizing communications technology that enables face-to-face contact as a means to reduce some travel. The study also recommends educational programs targeted to women and other underrepresented groups to not only develop leadership potential, but to make them aware of the opportunities that are available to them.

While implementing specific strategies is important, Beckton said that a more profound shift in the "businessas-usual" mindset will be necessary to tap the full potential of the diverse groups that can help avert the workforce shortages looming ahead for mining and other industries. An example she cites from the study is establishing

\section{Shadia J. Ikhmayies}



spent much of her life

\section{scaling mountains.}

The first was located behind her childhood home in a Palestinian refugee camp near Hebron. While being part of her playground, it also offered her an early glimpse into the world of science. "I tried to understand everything around me and asked a lot of questions," she said.

At the age of 10, her family moved to Jordan and she began her studies in schools established by the United $\mathrm{Na}-$ tions for refugee children. "In school, it was my chance to know more and learn more, and my teachers encouraged me," she said. Ikhmayies quickly advanced to first in her class, supplementing her school work with her own explorations. "I read any book or magazine that I found," she said. "I tried to understand how the television and radio worked and would open batteries to examine their constituents."

Fueled by her curiosity, Ikhmayies enrolled in the University of Jordan as a physics major and began her ascent

\section{Assistant Professor, \\ Department of Basic Sciences}

\section{Al-Isra University}

Jordan

up a different type of mountain - as a woman trying to achieve scientific excellence in a culture with very different values. "In developing countries such as Jordan, science is not a priority, so universities and foundations do not esteem scientists," she said. "People are categorized according to their origins and their tribes, and this determines their positions and places of work. Smart persons have difficulty finding a job in a place that supports their specialization or interests."

"In most cases, men do not trust women as scientists or leaders in any field," she continued. "I must struggle to prove that I have more experience or am more qualified than men."

Ikhmayies's tenacity over the years has enabled her to secure a faculty position at Al-Isra University. Her research continues her Ph.D. thesis work in the production and characterization of $\mathrm{CdS} / \mathrm{CdTe}$ solar cells, with a current focus on II-VI thin films and bilayers, as well as computational efforts in carbides and nitrides. She notes that her most effective strategy in pursuing her career has been "sharing through teamwork" as a pathway to interactions with other scientists and to ensure inclusion in scientific activities. She also actively seeks out professionals with an interest in renewable energy outside of work,

\section{"If quality and}

experience are

always the criteria

in choosing people

for any position,

the number of

female scientists

and engineers will

increase."

primarily through volunteering with TMS and other professional societies. Ikhmayies likewise supports and encourages her students to engage in scientific pursuits beyond the university, so that they can expand their horizons as well.

Forging linkages with the greater scientific community is not only good for the individual researcher, but important for the continued development of Jordan, Ikhmayies believes. The experience and exposure gained by attending conferences and engaging in projects on an international level, she maintains, are particularly important to advancing the role of women. "When qualified and highly experienced women fill important positions in universities and scientific foundations, their success makes it clear that women can do anything men can do," she said, "and this can begin changing the misconceptions about our abilities." 
practices that emphasize and enable the transferability of experiences and skills to leadership positions, rather than detailed knowledge of specific operations.

As of 2011, women comprised $18.62 \%$ of the overall workforce in the Canadian mining, gas, and oil industries, while $12.30 \%$ of the positions in senior management were held by females. ${ }^{4}$ Beckton said that the few women employed in these industries tend to enter through the "support side" rather than working directly in mining operations. Promotions, however, generally go to those with the operations background.

"In other sectors, such as finance and government, senior leaders are expected to move from one department to another," Beckton explained. "Mining could likewise benefit from bringing people into senior positions and on their boards with a broader experience than operations. The mining industry needs to re-examine its traditional pathway to the senior level and make a paradigm shift on what qualities are really nec- essary for those positions. You don't need to know how to do everything in a mine in order to be an effective leader. You can learn that knowledge. What is needed are new insights as to how mining is perceived by its customers, business partners, and the public. You can only achieve that by accessing the full spectrum of potential talent."

Establishing more women and other under-represented groups in positions of leadership, said Beckton, will help build networks of mentoring and support for these individuals throughout

\section{Viola L. Acoff}

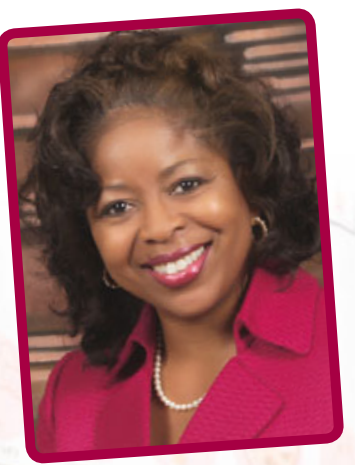

Watching her father

manage the family

construction company in

Bessemer, Alabama, gave

Viola Acoff an early

appreciation as to how

\section{math and science could}

\section{be applied to a career.}

Born ninth in a family of 10 children, Acoff and her siblings all pitched in to help with the business at a young age, from performing office chores to working on job sites. Her mother also made sure that the Acoff home was filled with music, beauty, and creativity. (Acoff, in fact, has written and recorded songs with
Professor and Head,

Department of

Metallurgical and

Materials Engineering

The University of Alabama, Tuscaloosa

USA

her family's gospel singing group.) It was at the age of 10 , when her older sister decided to major in engineering, that Acoff discovered a career path that could build on the abilities and work ethic that had been instilled in her as a child. "When my first sister started college, I was able to learn, first hand, what engineering entailed. The fact that it allowed me to combine my interests in math, science, and creating things kept me intrigued from the age of 10 until now. I have never wanted to be anything else but an engineer."

Acoff cites the ongoing inspiration offered by her family as a significant factor in her success. Four of her six sisters majored in engineering, providing her with positive exposure to the field, while her mother "always made me believe that I could accomplish anything." As her career has evolved, she underscores the importance of a different "family" - the network of colleagues and mentors that she has built through her participation in a number of professional societies, including TMS. "This in-
"Bottom line, providing early exposure

to science and

engineering is vital to improving the numbers of women in these fields."

volvement created a support group atmosphere for me as a student, and attending regional and national meetings allowed me to gain a better perspective of the field," she said.

Looking to the future of materials science and engineering, Acoff highlights the positive role models and creative teachers of her own childhood as examples of how to develop talented young people - and especially young women - into successful MSE professionals. She also recommends that high school students consider participating in relevant camps to make sure engineering is a good fit. "Most students choose to pursue a career in science and engineering simply because someone told them to do so because they are good in math and science," she said. "Although being good in math and science is necessary, students need to get a better idea of how these skills are applied to make a more informed decision regarding their career options." 
the industry, which in turn, can make it more attractive for new professionals. At the same time, she stresses that "there needs to be more of a conscious effort to enable inclusion in the culture of the organization. Many decisions are made around casual settings - in the bar after work, on the golf course, in the restroom. There needs to be more opportunities developed that don't exclude women from these con- versations."

Beckton emphasizes that the intent of the study was to "show a path forward," rather than simply enumerating all of the obstacles to inclusion. Many companies, she said, have been working on the issues, but "there is still a lot of talk about the problems. A lot more action needs to be taken." And, while the study highlights individual companies that have taken significant steps to make changes within their organizations, Beckton observed, "It will take that kind of leadership industry-wide to shift to a more inclusive culture."

The recommendations outlined in the study, Beckton believes, can serve as guideposts, but the only way they can be broadly implemented is "by more sharing of best practices across the industry and a concerted commitment to making changes."

\section{Melis Şerefoğlu}

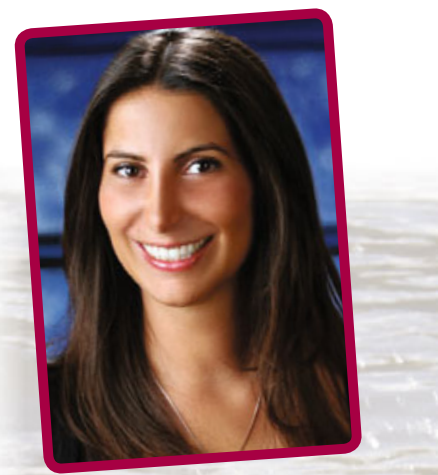

\section{Melis Şerefoğlu knows}

\section{quite a bit about making}

\section{progress against currents,}

\section{both literally and}

\section{figuratively.}

In high school and her early days as an undergraduate student at the Middle East Technical University (METU), she was passionate about competitive rowing, eventually winning a spot on Turkey's national rowing team. The rigors of training six days a week in such a grueling sport while contending with the demands of her college classes, however, compelled Şerefoğlu to make a difficult choice. "My first-year grade point average helped me realize that being a good engineering student and a good rower at the same time was not realistic," she said. Şerefoğlu then more fully devoted her energies to her studies, although to this day, she is careful to maintain a balance between work and her personal interests.
Research Assistant

Professor, Department

of Mechanical

Engineering

\section{Koç University}

\section{Turkey}

"Sports and social activities give you a chance to improve yourself in areas other than science, and that gives you a wider perspective on life," she said. "Rowing taught me not to listen to my exhaustion, and I learned important lessons about not being rewarded every day, being patient, not to lose hope, and to have faith that the long-lasting effort would pay off."

Applying those life lessons to her coursework did pay off significantly, and Şerefoğlu remembers, with particular pride, that she was able to score an " $A$ " from the "toughest professor in the department" in a physical metallurgy course. That experience shaped her in other ways beyond the satisfaction of a good grade, she said, because the professor, Sakir Bor, "encouraged us to think about the "why' and 'how.", Wrestling with those types of problems ignited her curiosity and set her on a path "to learn and understand how materials can form different structures."

Şerefoğlu's professional journey has taken her to three continents in eight years, as she secured her Ph.D. from Iowa State University under Ralph Edward Napolitano and completed postdoctoral research at the Institut des Nanosciences de Paris with Gabriel Faivre, Silvere Akamatsu, and Sabine
"Being a dedicated sportswoman and hard-working scientist are highly intertwined."

Bottin-Rousseau. "I have been so lucky to have had the chance to work with these people, who are not only great scientists, but also great friends and mentors that helped show me the way," she said.

Now building a career in her homeland, Şerefoğlu hopes to someday establish her own laboratory group on solidification and crystal growth dynamics, while also playing a lead role in "educating the new generations in Turkey." To ensure that those new generations choose science and engineering as a career, "I think we have to change how the public sees scientists," she said. "When you are young, it can be hard to follow a path that might seem unconventional, even though it may end up being what you dreamed of all your life. This is particularly the case for girls, since there are not that many women in these fields. We have to demonstrate to them that being a scientist gives you the opportunity to do something that no one has ever done and discover things that no one ever thought about. In lots of occupations, you may end up doing basically the same thing for 30 years over and over again. But in science, you always have the opportunity to start a new adventure." 


\section{UNINTENDED BIASES}

While structured initiatives can be effective in addressing issues such as pay equity and professional development, tackling often unconscious perceptions and practices that have been ingrained with time is a much more elusive challenge. Among a number of studies that have recently examined the impact of these potentially damaging workplace norms is The Athena Factor: Reversing the Brain Drain in Science, Engineering, and Technology, published by the Har- vard Business Review in 2008. The Athena Factor reported that, while women constitute 41 percent of all science, engineering, and technology professionals at the lower rungs of the career ladder, more than 50 percent of them eventually leave, with the peak of the exodus at around the 10-year career mark. This is twice the rate of men in similar professions and higher than the attrition rate of women in law or investment banking. A "macho culture" that "is at best unsupportive and at worst hostile to women" was cited as a major factor leading to the sense of isolation, stalled potential, and frustration that caused many women to leave science and engineering at the crucial mid-point of their careers. ${ }^{5}$

The good news out of The Athena Factor was that some inroads had been made in helping women overcome some of these challenges. Highlighted among 14 programs that had started to demonstrate some success was Alcoa's Women in Operations Virtual Extended Network (WOVEN), a pilot tested in the company's Global Primary Products Group with the intent of facilitating the transition

\section{Amber Genau}

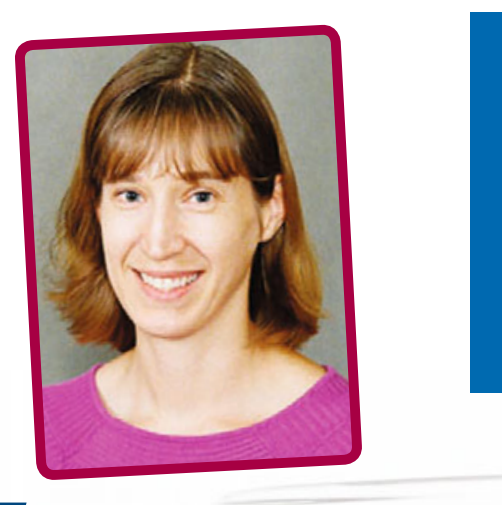

For Amber Genau,

\section{it all started with}

\section{bubbles.}

"As a kid, I always wondered where the bubbles came from at the bottom of a pot of boiling water," she said. "I clearly remember my excitement in school one day when science finally explained it to me. On my best days of research, that excitement of discovery and understanding is still present."

Genau is happy to pass that excitement on, whether it's teaching undergraduate and graduate classes, supervising research assistants, leading a study abroad course in Germany or organizing a summer materials camp for area high school students. "I decided that I wanted to become a professor when I was a sophomore in college," she said. "I hope I can make a difference in the lives of my students and perhaps even influence the way that

\section{Assistant Professor,}

Materials Science and

Engineering Department

The University of

Alabama, Birmingham

USA

engineering is taught outside my own classroom."

On that point, Genau believes that engineering education could be improved by wider adoption of cooperative learning techniques and other approaches focused on developing a more diverse student body. "There is a wealth of research out there about teaching strategies that improve the experience of minority students, including women, but they have yet to gain much real traction in most classrooms," she said.

Genau noted that her own experiences as an MSE student and professional have been quite positive. "Although I have been aware of being a minority in my classes and my research field since high school, I have never felt any significant challenges as a scientist because of my gender," she said. "I am extremely grateful to the generations of women who came before me and made that possible."

While the demographics of materials science and engineering have changed, Genau observed that the
"Materials engineers

tend to be creative, interesting, and

well-rounded

people."

rules governing advancement in an academic career have been slow to keep up with the perspectives and potential contributions offered by a more youthful, diverse workforce. "The standard paradigm for success in academia requires an extraordinary commitment of time to research and the pursuit of research funding, often at the expense of everything else, including quality teaching and a personal life," she said. "Many people I know aren't in a position to make - or are interested in making - the kinds of sacrifices necessary to be successful in the current system. I think there needs to be a serious reconsideration of expectations and priorities if we want to continue to attract the best new teachers and researchers into our universities."

Genau's own research interests have focused on metal solidification and microstructural analysis, shaped by her larger goal "to use science to solve problems. I've found the materials field to be a great combination of the basic science I love and interesting applications." 
of women to operations from other departments. Alcoa was also a major co-sponsor of the study.

Bias that creeps into decisionmaking and interactions, however, is not confined to the traditional male demographic. In 2012, a study published in the Proceedings of the $\mathrm{Na}$ tional Academy of Sciences found that unintended gender biases can be exhibited by both male and female science faculty members. The study reports on an experiment in which job application materials were distributed to a sampling of science faculty at six universities. The materials were identical except for the indication of the applicant's gender. At about the same rate, both male and female faculty rated the "female" applicant lower in terms of hireability, competence, and potential for mentoring. ${ }^{6}$

"I was surprised to see the magnitude of the bias so equally distributed across gender, age, and other subgroups," said Corinne Moss-Racusin, lead author of the study and postdoctoral associate at Yale University.
Moss-Racusin said that her work builds on previous research into perceptions of how well suited women are to science and math. "Even though we argue against these types of stereotypes, they are rooted in all of our experiences-Both men and women are equally exposed and it becomes equally part of our culture," she said.

In the academic world, these subtle biases can have a marked impact on the evolution of young careers. That's why, said Moss-Racusin, a study such

\section{Virginia S.T. Ciminelli}

E

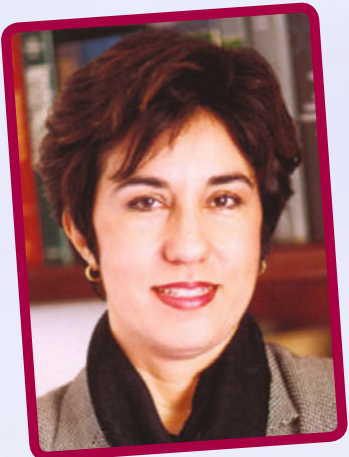

\section{experience are not the}

\section{only factors that women}

\section{need to take into account}

\section{in order to advance in}

\section{science and engineering,}

\section{maintains Virginia}

\section{Ciminelli.}

"Women usually believe that if they do it right, recognition will come," she said. "This underestimates the strength of socio-cultural factors, as well as the role of professional networks on career opportunities and achievements. Women are generally not trained to occupy a position of leadership in the professional, androcentric universe."

Ciminelli herself has achieved a number of leadership positions, in-

\section{Professor, Department of Metallurgical and Materials Engineering \\ Universidade Federal de Minas Gerais (UFMG)}

\section{Director, National Institute of Science and Technology on Mineral Resources, Water, and Biodiversity}

\section{Brazil}

cluding being the first full female professor appointed to the School of Engineering at UFMG, and being the first woman elected to the engineering section of the Brazilian Academy of Sciences. The first time she applied for a job, however, she said that the board decided not to hire her based on her gender, rather than her qualifications. "I am a person driven by challenges. These difficulties made me grow and create my own way," she said. "But, I recognize that this does not apply to everyone."

In light of her own experiences, Ciminelli believes that providing young women and under-represented minorities with the tools and acumen to advance their careers and overcome any obstacles should be part of their educational experience. "They need to be better prepared to understand the rules of the game," she said.

The rules need to change, too, notes

\section{"The model that we}

\section{currently follow no}

longer applies in

many societies.

It needs to be

re-evaluated to

support the many

other roles that

women offer."

Ciminelli. The post-World-War-II industrial production model that society still generally adheres to "was balanced in terms of gender responsibilities, but lacked opportunities for women regarding career development" she said. "Today, we have more career opportunities, but no balance, as women are expected to perform professionally like a man without taking into account their other roles in society. We also need to recognize that young professionals, in general, treasure balance in their lives more so than previous generations." Ciminelli also cautioned that these changes should not just be directed to supporting the "best and the brightest," saying, "It is important to create opportunities for the average female professional, instead of focusing only on the outliers." 
as hers should not just lead to more studies, but "be the first step in an honest conversation." For this reason, Moss-Racusin is focusing her cur- rent work on interventions. Some of these recommendations, she said, are pretty straightforward, from developing processes to ensure consistency in mentoring experiences, to raising awareness that biases do indeed exist, even among the most egalitarian of individuals.

\section{Catherine Rae}



\section{Science was}

\section{Catherine Rae's}

\section{destiny, starting with her}

\section{early childhood years}

\section{spent in a tent in}

\section{sub-Saharan Africa}

\section{where her father worked}

\section{as a field scientist.}

Further inspired by the space race of the 1960s, she earned her bachelor's degree, with highest honors, and a doctorate from Oxford University. Her academic excellence then led to a prestigious research fellowship with Rolls-Royce in Cambridge where she worked on materials for gas turbine engines.

Then, life happened.

Rae decided to take a few years off to start her family of three children, confident that her credentials would assure a clear path back to her scientific career. That proved not to be the case. "When I was ready to go back, the country was in the middle of a recession - No one was hiring," she said. "I applied for teaching jobs, but was generally overqualified for

\section{Reader in Physical}

Metallurgy, Department

of Materials Science and

Metallurgy

Cambridge University

U.K.

them, and was living in an area that had no industry matching my expertise." Adding to the complexity of the situation was a lack of access to established childcare for Rae's stillyoung children. "I ended up running my own after-school club, which just added to the time pressures," she said.

Rae eventually secured a series of short-term contracts with the University of East Anglia, teaching pre-university science to "an inspirational group of people who had, for one reason or another, left education." With great pride, Rae recalls that several of her students in the program eventually went on to complete full science degrees, graduating at the top of their classes. "They taught me that you can do anything if you try hard and believe in yourself," she said. The parttime, unstable nature of the work, though, eventually compelled Rae to accept a research administrator position. It was a more secure job, but "I hated it," said Rae.

Prior to that decision, Rae had written a letter to Robert Broomfield, whom she had worked with during her days at Rolls-Royce, "asking if there was any way they could fund me to do research in some capacity." Eighteen months later, while she was opening mail in her office job, "out of the blue, I was offered a postdoctoral position in Cambridge." Her letter to Broomfield had apparently been circulated from desk to desk,

\section{"The most important}

\section{thing is that women}

have confidence in

their own abilities to

do science from the

start-the rest is just

organization."

eventually finding its way to Roger Reed, then at Cambridge and now at the University of Oxford, who had just been awarded a large grant to do research in Rae's field of superalloys. "I thought, at the time, that my chances of making a career of this at the age of 41 was remote, but I had to try," said Rae. She then accepted a series of short-term, postdoctoral positions and was appointed to a university lectureship within five years.

Today, Rae runs a $£ 2.25 \mathrm{M}$ doctoral training center, on top of her teaching and research responsibilities. While she believes that a number of good initiatives to retain female scientists have been introduced since the early days of her career, she decries "popular research" that has emerged promoting gender differences in aptitudes. "When I was growing up there was prejudice, but we all believed we were equal," she said. "It has become the default opinion for intelligent women to claim that men and women are equal-whatever that meansbut have 'different' talents. "This undermines the confidence women have in themselves at a very young age. The most important thing is that women have confidence in their own abilities to do science from the start - the rest is just organization." 


\section{CleARING PATHWAYS}

Elizabeth Holm, Professor of Materials Science and Engineering, Carnegie Mellon University, and the 2013 TMS president, believes that MSE can learn from other professions - most notably the medical community-on how "to create an environment where people of all kinds, with all types of ideas and talents, can find a role that is fulfilling to them."

"This is not just a gender-based issue," she said. "We are simply not getting enough of anyone with the different perspectives we need to find so- lutions to the complex and challenging problems that society now faces."

Holm says that her priority for TMS is "to make sure that all people in our field are getting the support that they need to be the best at their profession that they can be."

"I believe where TMS can have the

\section{María Victoria Canullo}

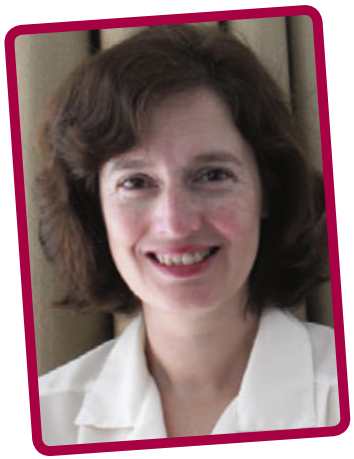

Each year, Aluar's three

primary cast houses in

Puerto Madryn,

Argentine Patagonia,

produce 460,000 tonnes

of aluminum that is

\section{solidified into high}

\section{quality products and}

\section{marketed throughout}

\section{the world.}

María Canullo and her team are responsible for the process engineering that makes that possible.

While her 16-year career at Aluar has been highly successful, Canullo recalls that the journey has not been without its challenges. With a Ph.D. in plasma physics, Canullo had been on track to pursue a career in academia, with her sights set on astrophysics and probing the mysteries of the night sky. "As I neared the end of my Ph.D.,

\section{Head, Metallurgy}

Department

Aluar Aluminio

Argentino SAIC

\section{Argentina}

it was very clear that the opportunities for a permanent academic research career were becoming increasingly difficult here in Argentina," she said. Reluctant to leave her homeland, she decided to "seize the opportunity" to work in metallurgy at Aluar.

Her transition to a completely different field of expertise, based in a plant environment rather than an academic setting, meant the Canullo had to "be re-trained completely. However, with good and patient colleagues and an open attitude to learning new things - not only technically but also in the ways and culture of the engineering world-I soon found the job exciting." In addition to providing extensive in-house development, Aluar also supported Canullo's enrollment in several master's level classes in materials science, as well as her pursuit of a masters in business administration degree. She credits being shaped during her career in academia in "an environment where ideas could be communicated openly, without prejudice" for facilitating her learning during this period. "This helped me think for myself," she said.

At the time Canullo started with Aluar, she was one of a very few professional women working at the plant. Since then, their ranks have grown significantly, although Canullo said that more can be done to foster
"Assessing the true abilities of others in

particular areas-

and how to value

them-is what really

matters."

a truly inclusive environment. "Several women are now in senior positions, although none have yet broken through the traditional 'glass ceiling," she said.

An important strategy for achieving this, Canullo believes, is attracting more women to industry to work in scientific and engineering positions. "We need to do more to encourage achievement, interest, and curiosity in science and engineering at an early age, in general," she said. "For young girls, in particular, it's important to introduce them to female role models that enable them to see that people like them can be successful in these fields. This includes emphasizing that modern industry offers many opportunities for career development."

Once women and other diverse groups have been established as key contributors in an industrial environment, honesty and commitment are still required to seamlessly integrate their perspectives and talents, Canullo said. "Some people still associate science and math as 'male' fields and humanities, social sciences, and arts as 'female," she said. "Understanding this bias can affect your attitude. The very act of identifying a stereotype begins the process of dismantling it." 
greatest impact is in that vulnerable period when the educational process ends, and you start embarking on your early to mid-career," she said. "We know that this is where there is the most peril for women to leave the profession. But, this is also where we can provide the professional development, networking, and career initiatives that can impact on attitudes and provide people with the skill sets they need to be successful in their careers and make their way through a not-yetdiverse workplace."
Like Bowman, Holm also believes that the unique aspects of MSE can give rise to its own strategies, building on its particular strengths. A step in exploring this potential is the first TMS summit that explores diversity and inclusion in the minerals, metals,

\section{Mary C. Juhas}

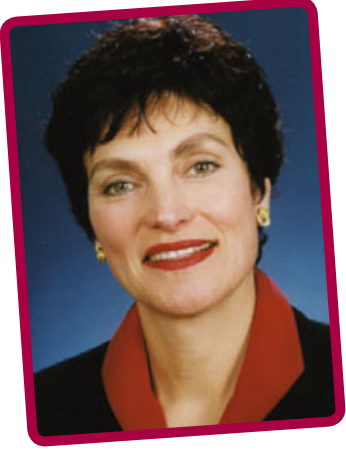

66

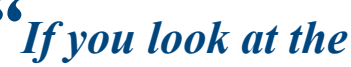

\section{numbers of women}

who graduate with

\section{engineering degrees}

\section{and remain in the field,}

the news is okay but not great," says Mary Juhas.

"The easiest-but not quickestway to improve the culture is to increase the female student cohort population to establish peer support," Juhas continued. "After several years, an infrastructure of mentoring by role models can be established. We have seen this model in medicine and law, but engineering still lacks the critical mass to achieve this in most sub-disciplines."

With engineering facing a critical workforce shortage in coming generations, Juhas has made the evolution of a more inclusive professional culture her life's mission for more than a decade. Women and other under-represented groups offer a well-spring of new talent and ideas, but Juhas said that often subtle barriers remain to making engineering an attractive, welcoming career choice for them. "Even the repeated use of masculine pronouns reinforces the
Associate Vice President

for Gender Initiatives

in STEMM (Science,

Technology, Engineering, Mathematics \& Medicine)

\section{The Ohio State University}

\section{USA}

message that 'he' equals engineer and 'she' doesn't necessarily fit," she said.

In her role at Ohio State, Juhas works with academic leaders to facilitate recruitment, retention, and advancement of female faculty members from diverse populations. Key to her approach is looking at the total person to accommodate life decisions and relationships, as well as recruiting professional expertise.

"There is a growing number of professionals graduating from science and engineering programs nationwide at all levels, but especially at the Ph.D. level," she said. "When the partner of the 'primary' hire is unable to secure a career-satisfying position, the risk of losing the couple becomes great. It is well worth the initial investment of time and effort to address the career fit of both partners."

Juhas has carried the message of inclusion far beyond the Ohio State campus through her work with the U.S. National Science Foundation (NSF) to help promote the ADVANCE (Advancement of Women in Academic Science and Engineering Careers) program, as well as providing leadership to other NSF programs focused on broadening participation of under-represented groups in science and engineering. As a TMS member, she serves as chair for the organization's Women in Materials Science and Engineering Committee, with

\section{"Always be true to}

yourself and don't try

to fit into a role that is

defined by others."

the goal of developing programs that address the professional needs of women who are pursuing a career in MSE.

Looking back, Juhas believes that these and other strategies have generally had a positive impact. "I think there is more available support now for women engineering students through formal networks," she said. "Many programs include mentoring from women who are working as engineers across the private sector/government/academic spectrum. Most large companies also have employee resource groups that can be quite effective." Real and lasting culture change, however, has to occur at the individual level, Juhas continued. "All the well-intended diversity policies coming down from upper management cannot fix the climate issues that women face locally on a daily basis," she said.

On this point, Juhas again emphasizes the importance of effective role models, drawing from her own experience. "I cannot remember a time when I was NOT interested in science. My earliest role models were girls who loved to explore science. I wanted to be like them. Later on, I was attracted by the idea that a scientific career was a pathway to finding answers to questions about everything around us. I guess that is where my eventual interest in engineering nucleated. Then, came the realization that there was such a dearth of women role models."

"That's what inspired me to remain in the field." 
and materials sectors, which Holm is organizing. (For additional details, see "In the Final Analysis" and Holm's Presidential Perspective, "Planting the Seeds of Diversity" in this issue of $J O M$.) The intent is to capture, develop, and share tangible guidance, tools, and approaches to making MSE a model of inclusion among engineering disciplines.

Within this context, Holm emphasizes the need to seek solutions and make forward progress, with the totality of the MSE profession-not just target groups - being part of the solution. As someone who entered MSE when very few women worked in the field, Holm described it as a "major victory" that a woman in the profes- sion is considered the norm, saying, "Even though we have not statistically hit 50/50, we have come a long way since the days when you would overhear at a conference, 'Did you see that girl giving the talk."'

The goal now, said Holm, is to get to the point in MSE "where there is no longer an issue to talk about. We need to work to the next level where all differences are erased, where every single class of diversity is welcomed, and no one ever stands out in a negative way because of who you are. All that matters is that you can contribute, without any barriers."

\section{References}

1. Keith J. Bowman, "Gender Diversity Changes in a Small Engineering Discipline: Materials Science and Engineering", Equality, Diversity and Inclusion: An International Journal, 2011, Volume 30 issue 2, pp. 127-144.

2. A.-F. Gilbert, "Disciplinary Cultures in Mechanical Engineering and Materials Science: Gendered/ Gendering Practices?", Equal Opportunities International, 2009. Vol. 28 No. 1, pp. 24-35.

3. Brian L. Yoder, Engineering by the Numbers, American Society for Engineering Education, 2012. 4. Centre for Women in Politics and Public Leadership, The Pathway Forward: Creating Gender Inclusive Leadership in Mining and Resources, Carleton University, Ottawa, ON, November 2012.

5. Sylvia Ann Hewlett, Carolyn Buck Luce, Lisa J. Servon, Laura Sherbin, Peggy Shiller, Eytan Sosnovich, and Karen Sumberg, The Athena Factor: Reversing the Brain Drain in Science, Engineering, and Technology, Harvard Business Review, May 2008

6. Corinne A. Moss-Racusin, John F. Dovidio,, Victoria L. Brescoll,, Mark J. Graham,, and Jo Handelsman, "Science Faculty's Subtle Gender Biases Favor Male Students," Proceedings of the National Academy of Sciences of the United States of America, October 9, 2012. Vol. 109, no. 41, pp. 16474-16479.

\section{Nicole Stanford}

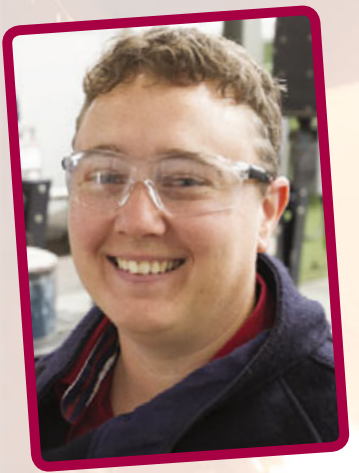

\section{The conversation still}

\section{makes Nicole Stanford,}

\section{an expert in magnesium}

\section{alloy development and}

\section{steel strip casting, angry.}

"While working on my own project, I was told once that foundry shoes and coats weren't made in women's sizes, so I would not be able to use the equipment," she said. "Not only is that totally untrue, it's also against federal law to discriminate against people on the basis of their size or gender." While this situation was quickly resolved, Stanford said that it is indicative of ingrained perceptions that still exist about women's roles and abilities.

\section{Senior Research}

Academic, Institute for

Frontier Materials

\section{Deakin University}

\section{Australia}

"My most significant challenge as a female scientist and engineer has been to break the notion that my role in a group research environment is to do the microscopy," she said. "Electron microscopy is a field of materials that is well represented with women, but there have been many occasions where it has been assumed that these "clean" roles are the only ones that I am qualified to carry out. There is still a reluctance to send women into roles with heavy machinery and hot materials."

"Once people get to know me, they quickly come to understand that I get involved with all aspects of my research," she added.

And, while many organizations have mounted diversity initiatives, Stanford feels that many still fall short in addressing obstacles women face in pursuing a career in science or engineering. "Many universities in Australia have been designated "Employers of Choice for Women," but this doesn't actually translate to anything tangible

\section{"Developing my}

support base with all levels of people in

my department has

been a patient

process of building

trust and earning

the respect of my

colleagues."

for the struggling female scientist," she said. "I think women tend to be more willing to leave their job for the benefit of their children. Consequently, if women are faced with poor job security, or the need to move a large distance to maintain a career in science, they are more likely to opt out and look for something new."

Stanford believes that one of the most effective ways to deal with these issues is to not let them go unchallenged. "Women need to make their opinion heard," she said. "It's really only by making people have the conversation that we force them to reconsider their viewpoint." 


\section{PLAN NOW TO BE PART OF THE SOLUTION}

TMS hopes you've been inspired by the ideas and stories of the individuals who have contributed to this special JOM topic on diversity in MSE. We invite you to continue this dialogue at a unique TMS summit that is now being planned to identify issues, best practices, and solutions to achieving greater diversity and inclusion in the minerals, metals, and materials sectors. It is scheduled for July 2014 , at a location that has yet to be determined.

The summit is dedicated to the work and legacy of Ellen Swallow Richards, who bridged tremendous cultural divides to become the first woman admitted to the Massachusetts Institute of Technology and later accepted as the the first female member of AIME (American Institute of Mining, Metallurgical, and Petroleum Engineers). Her strategy to make an impact on the patriarchal realm of scientific thought and practice was pragmatic for her day. "I hope that I am winning a way which others will keep open," she wrote to a friend in 1872. "Perhaps the fact that I am not a radical, and that I do not scorn womanly duties ... is winning me stronger allies than anything else ... I am useful in a general way, and they can't say study spoils me for anything else."

Thankfully, times and attitudes have changed, but strategies are still needed to finish the work begun by Ellen Richards and other pioneering individuals to open MSE to all the ideas, opinions, talents, and viewpoints it requires to address the world's increasingly complex needs for materials. Watch the TMS website and the pages of JOM for details of the summit in the coming months. As Ellen Richards also said, "We never can tell how our lives may work to the account of the general good, and we are not wise enough to know if we have fulfilled our mission or not."

\section{Margaret Hyland}

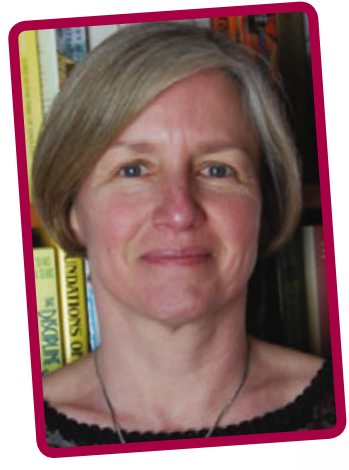

\section{At first, it seemed like a}

\section{disaster.}

Margaret Hyland was at the helm of a major research program for one of the first times in her career when the photoelectron spectrometer failed. "It was a critical piece of analytical equipment, and it was taken out of action for the good part of a year," she recalled. "I had been convinced that this equipment was essential, because I had made assumptions about the chemistry of the process we were studying. Out of necessity, we turned reluctantly to other techniques." To the surprise of Hyland and her team, "moving to other methods opened up a whole set of insights that we would either have never or much more slow-
Professor, Chemical and Materials Engineering

Deputy Dean, Faculty of Engineering

University of Auckland

New Zealand

ly gained. This taught me not only the value of serendipity, but also the danger of being too close-minded in your thinking."

That perspective has guided Hyland since in both her personal and professional experiences. As an example, she notes, "I eventually realized that I didn't have to manage my career in the same way or at the same pace as my male colleagues. Certainly, I was a little slower off the mark, having decided that I wanted to make sure that I was able to spend the time I wanted to with my children. But after they were older, I found that I was able to accelerate, and in the middle part of my career, I have made faster progress. I also noticed that having children was very positive for my professional development. It taught me a number of strategies about people management,
"We should be

promoting the human

side of engineering

and science."

management of expectations, and sticking to decisions, that I have found very useful in my professional life."

Hyland, who currently lists aluminum reduction technology and surface engineering as her research interests, said that she was first attracted to science in high school because "there were so many more of those 'wowthat's-so-cool' moments in science that I didn't get in other subjects." The second youngest in a family of 12 , she also jokes that she "liked the thought of doing something that none of my older siblings had done." She believes that the most significant draw to an MSE career, though, is the potential impact an individual can have on the world-an aspect she thinks should be brought out more in recruiting new professionals. "We should be showing that through engineering and science, you can do things that really matter," she said. "You can work on the big issues that affect society." 


\section{Iman El-Mahallawi}

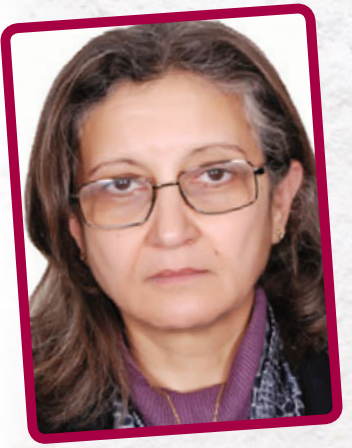

Metallurgy was very

much a "family business"

for Iman El-Mahallawi.

Her uncle led the initiative to establish the Egyptalum aluminum plant in the desert of Nag Hammady, while her father took her on regular "field trips" as a teenager to area
Professor, Materials and

Metallurgical Engineering

Cairo University

Director, Centre for

Renewable Energy

The British University in Egypt

Egypt

\section{Tresa Pollock}

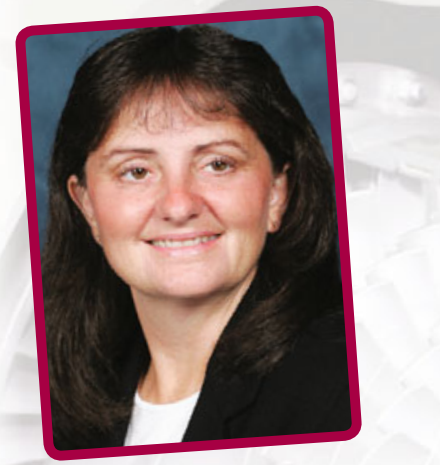

\section{Tresa Pollock's career}

in materials science and engineering took flight

when she participated

in a co-op program at

what is now Rolls Royce

in Indianapolis as an

undergraduate at Purdue

University.

\section{Alcoa Professor and \\ Chair, Department of \\ Materials}

University of California, Santa Barbara

USA

"Seeing the connection between my academic work and its application in aircraft engines was exciting," she recalled. "I noted that all the interesting projects were headed by engineers with Ph.D.s, so that motivated me to go to graduate school."

Since that time, Pollock has distinguished herself as a leading expert in high-temperature materials, and her contributions to the emerging discipline of integrated computational materials engineering (ICME) includes chairing the committee that produced the groundbreaking U.S. National Academies study that first articulated ICME's potential impact on the future of MSE.
"Materials

engineering is the future of human

progress."

hallawi voiced concerns for the future of women in her country. "Unfortunately, in Egypt, I think that women were better supported in the past than now. Women should just be given an equal opportunity. We don't need any special privilege for being womenjust treat us the same as men. There is a misconception that women cannot take the hard work required by science and engineering. This has to be addressed from the reality that women from all over the world show great capability to thrive under stressful or challenging conditions."

"We need more

role models and a greater realization of how engineering is unique in its ability to solve many societal problems."

Pollock has broken ground on other fronts by serving as the first female TMS President in 2005, as well as a number of other leadership roles. She believes that today's engineering students could benefit from her experience by making internships a priority "and learning as much as possible about the scope of engineering and what can be accomplished."

"First and foremost, you need to find good colleagues and good mentors," she continued. "Be confident. And, a sense of humor never hurts." 


\section{Christina Viklund White}

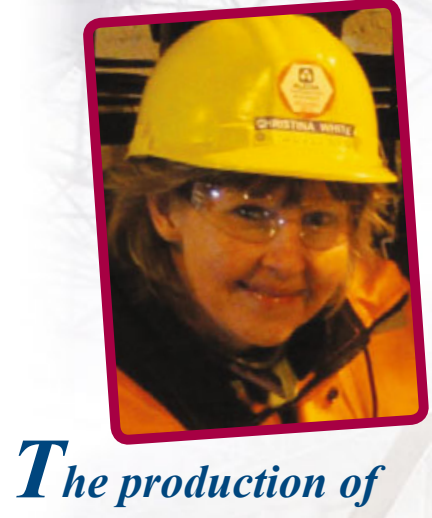

primary aluminum by

carbothermic reduction is

a new technology that can

significantly reduce the

energy now required by

the Hall-Héroult process.
Process Manager,

Carbothermic Project

Alcoa Norway

Norway

Its successful development and implementation would represent a game-changing innovation in the aluminum industry, while also contributing to a more sustainable, energyefficient world.

Christina White stands on the horizon of that new day as the process manager for Alcoa's carbothermic research and development project. Her responsibilities include planning and managing test campaigns, as well as interpreting the test data generated by Alcoa Norway's development furnace. "This is really an exciting opportunity," she said.

\section{"Individual}

\section{characteristics and}

\section{competencies are}

more important than

\section{your gender.}

Advancing new and better ways to manufacture metal has defined White's career since her early days conducting metallurgical pilot plant testing as a research engineer for Swerea MEFOS in Sweden. "I don't think that I have been at a disadvantage being a woman in an environment as male-dominated as the metallurgical industry," she said. "In the end, it is your personality and competency that counts. The most important thing to remember is to be yourself. That is true in any situation, in any work environment."

\section{Julia R. Greer}

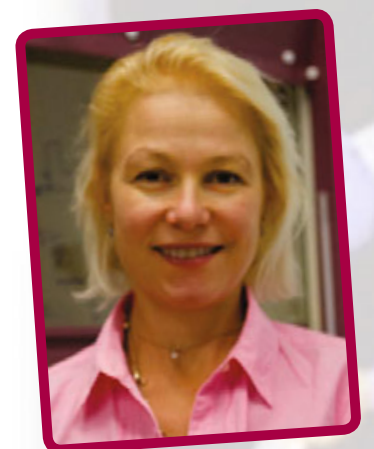

Professor, Materials Science and Mechanics

California Institute of Technology USA

\section{$W_{\text {ith most of her career }}$}

\section{still ahead of her, Julia}

\section{$R$. Greer is a force to be}

\section{reckoned with.}

A glance at her research group's website suggests just how multi-faceted Greer's life is. Her photograph shows her rollerblading to work, and amid the staggering list of scientific achievements, she proudly notes that she won the 2003 U.S. Open Concerto Competition. Fittingly, her lecture topic as the Balance it All?" being obnoxious."
"My most rewarding

moments are when

I can see that, with

my mentoring and

my help, I was

able to facilitate

Faculty Fellow Award was "A Scientist, a Parent, a Teacher, a Mentor . . . How to

Greer is quick to point out that her success has been shaped by many mentors and colleagues, citing her Ph.D. advisor, William D. Nix, Professor Emeritus, Stanford University, as particularly influential on her career. Occasionally, though, she has still had to contend with narrow-minded individuals. "I have certainly heard comments like, 'You don't look like a scientist.' What has been a useful strategy for me is 'tilling the field and keeping my head low'-Let my work speak for itself, but also defend my turf," she said. "It's important to have a healthy dose of assertiveness, without the transformation

of a student into a scientist."

"It's unfortunate that these stereotypes still exist, but the good news is that I have already seen things move in the right direction," Greer continued. "More and more women are entering science and engineering and are being recognized for their work. I certainly draw inspiration from the successful women around me. Many of us value and have benefitted from this 'sisterhood' that exists in science and engineering." 


\section{Megumi Kawasaki}

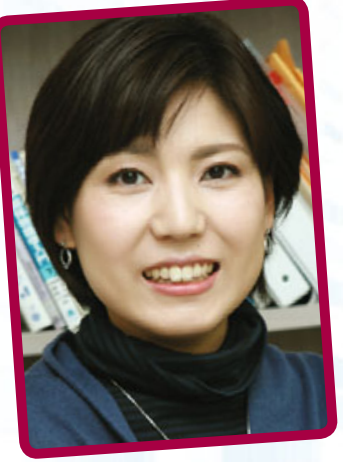

\section{Assistant Professor,}

Division of Materials

Science and Engineering

Hanyang University

\section{South Korea}

"There are very few female engineering students and almost zero female engineering professors in Japan," she said. "I could not really find anyone as a role model for my future."

With the advice and support of her B.S. advisor, Kenji Higashi, Kawasaki enrolled in the University of Southern California (USC) to complete her M.S. and Ph.D. under her thesis advisor, Terence G. Langdon. There, she was able to connect with many more female faculty members, saying "I then realized that I could do anything in this field."
"I realized that I

could do anything in

this field."

Kawasaki stayed at USC for her postdoctoral research and was eventually appointed a research assistant professor. She then had to make the difficult decision to leave her life in the United States and move to South Korea, where her husband had secured an assistant professor position. Today, as a junior faculty member at Hanyang, she is committed to opening her students to the opportunities that her mentors showed her. "There is still a very limited number of female engineering students and faculty in Japan and South Korea," she said. "We, as faculty members and advisors, need to support them more, and make sure they have role models to help show them the way."

\section{Hilda Kundai Chikwanda}

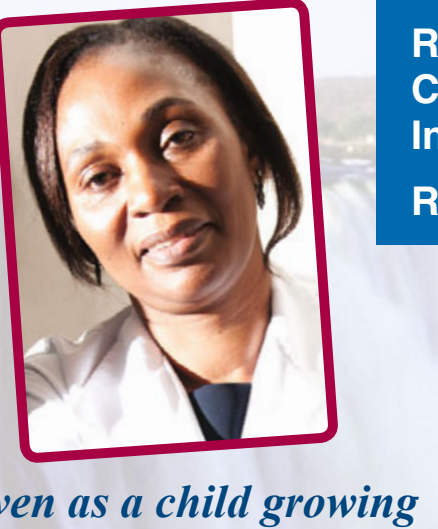

up in Zimbabwe,

Hilda Chikwanda was

intrigued by the larger

possibilities of science.

"My interest was not limited to the foundations of scientific knowledge, but also extended to relations between science, technology, and society," she said. She attributes her "excitement in science" for driving her to excel
Research Group Leader,

Council for Scientific and

Industrial Research (CSIR)

\section{Republic of South Africa}

in school: "I was mesmerized by discovering what science tells me about the world I live in," she said. "It is this passion that helped me make good marks in my science subjects." Her drive to do well in science was a critical factor in her primary education and early years of secondary school. "These were major milestones to me because, in the environment I was in, most girls could not get that far," she explained. She credits her parents for nurturing her confidence and ambition, saying "They had an open mind about the world, giving me equal opportunities to my older brother's and supporting me in what I wanted to do."

Chikwanda's academic excellence opened the door for her to complete an extra two years of senior second-
"A major focus of my life has been to work 'smart' to make a positive difference."

ary school-a privilege that generally was not accessible to other studentsand secure a scholarship to study metallurgical engineering at Donetsk Polytechnical Institute, Ukraine. She then returned home with her master's degree in hand to work as a metallurgist at the Zimbabwe Iron \& Steel Co. Chikwanda recalled that some of her male colleagues "would just look at me as a 'woman' and not an engineerThrough this, I learned to articulate my ideas very well."

Having since earned both a Ph.D. and an MBA, Chikwanda has most recently focused her talents on building a team at CSIR. "I am always passionate about what I do," she said. "I live everyday as a learning day and a happy day." 


\section{Spomenka Kobe}

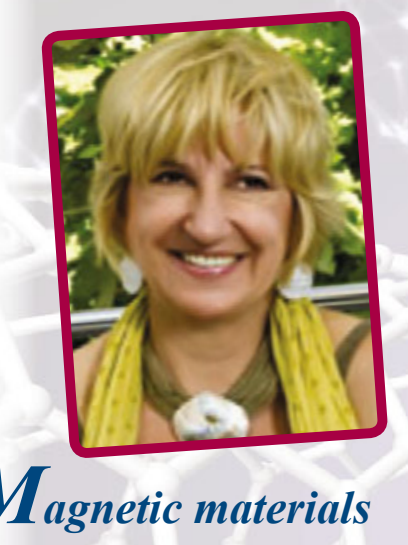

\section{have always held a \\ strong attraction for}

\section{Spomenka Kobe.}

"For me, this is the most exciting field of science," she said. "Studying and producing magnets, collaborating with industrial partners, and being involved with transfer technology has been exceptionally fulfilling."

\section{Head, Department for \\ Nanostructured Materials \\ Jožef Stefan Institute}

\section{Slovenia}

Kobe's work, starting very early in her career, has earned widespread recognition. Her Ph.D. research on producing permanent magnets based on intermetallic alloys of rare earth and transition metals to industrial-scale production won a Slovenian State Award for Scientific Research. Kobe also earned two subsequent awards from industry recognizing the successful transfer of the technology.

To open doors to other women in the field that she has loved and excelled in, Kobe has been actively involved in two recent initiatives sponsored by the European Commission to encourage more diversity in the materials scienc-
"My job is not work-

and I am aware that

not many people

have this privilege."

es. The DIVERSITY project is a pilot initiative that networks policy makers, human resources experts, and the science community to support inclusion of female scientists in materials research organizations at the decisionmaking level. The other, "Women in Nano," focused on increasing the visibility of women in nanoscience. Kobe believes that enhanced public understanding, as well as support of policy makers in Europe in developing strategies to recruit and retain female scientists, has had a significant impact, but "we are still far from having an equal number of female and male scientists in the field."

\section{Megan J. Cordill}

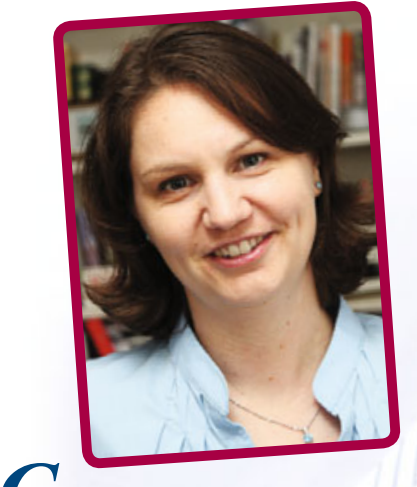

Growing up on a wheat and cattle ranch in the U.S. state of Washington, Megan Cordill would never have predicted she would be researching adhesion techniques for films on flexible substrates in Austria.

\section{Research Assistant/} Group Leader

Erich Schmid Institute of Materials Science, Austrian Academy of Sciences

\section{Austria}

"Science got me here," she said. "And, it shows that you need to see everything as a possibility and take chances."

She credits her mother for initially pointing out the possibilities of materials science by suggesting she study ceramics engineering to combine her interest in art with her aptitude in math and science. She also feels that because materials science is a smaller discipline, she was able to benefit from being part of a more supportive educational community. "I was never 'the lone girl.' Because there was always a small class size, both male and female students needed to work well together,"
"When people ask

me 'what is a materials scientist,' I tell them I

know what makes your smartphone work."

she said.

Cordill believes that keeping an open mind about options is an important life, as well as a career, strategy. "I don't believe that my job is the only definition of who I am or who I want to become," she said. "Circumstances in life may change what I do as a career, but that won't change who I am."

She also tries to model this approach for the female post-docs and students she supervises in her research group, saying, "I think showing female students that you can have a successful career in science and a full, rewarding life can have a significant impact." 


\section{Joalet D. Steenkamp}

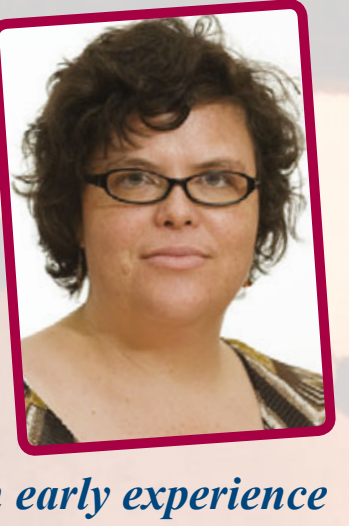

with a scanning electron

microscope enabled

Joalet Steenkamp to see

beyond the surface in

more than a few ways.
Consultant in Pyrometallurgy,

Multi Facet Consultancy

\section{Republic of South Africa}

"It was then that I fell in love with metallurgical engineering," she said. "I realized there was a whole world out there."

Steenkamp has since explored that world through several engineering positions in industry and is currently working on her Ph.D., while also managing her own consulting business. She cites her work on the pyrometallurgical aspects of the Iscor Heavy Minerals Project as a turning point of her career. "I joined the project during the detailed design phase on the client side and obtained a lot of experience with conducting desktop studies and
"I was fortunate to

have a very wise,

empathetic mentor

at a crucial stage in

my career."

doing pilot plant work," she said.

Steenkamp also believes that "working very hard at getting to know who I am and what I am supposed to achieve in this lifetime" is an important part of her professional and personal journey. "My advice is to do personality tests, go to workshops, and find out what it is that you enjoy doing in life," she said. "If something does not work out, learn the lesson and move on. Other opportunities will certainly come your way."

\section{Ellen Cerreta}

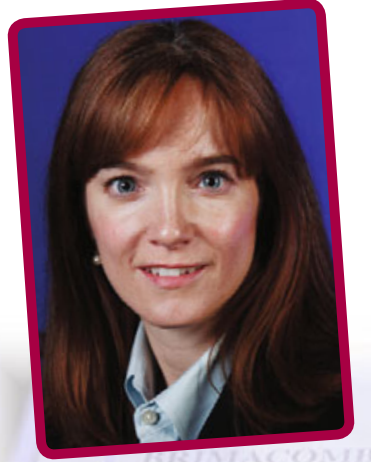

Deputy Group Leader, MST-8

Los Alamos National Laboratory

USA

example, it would sometimes be difficult to determine the correct balances between work and life, science and management, and career transitions."

Taking those lessons to heart, Cerreta has likewise placed a high priority on giving back to her profession. Even before she secured a postdoctoral fellowship at Los Alamos, she was volunteering her time and talents to her professional organizations. At TMS alone, she has reviewed papers for journals, chaired committees, organized symposia, and served on the Board of Directors. Her service and professional excellence was recognized by the 2013 Brimacombe Medal-TMS's highest honor for professionals at the midpoint of their careers.

Cerreta stresses the value of being able to maintain a balanced outlook on

\section{"TMS allows me to}

not only advance

my technical

background, but to

also see how others

in the profession are

successful."

life. "Science and engineering careers can be difficult and they include a great deal of peer review," she said. "I think that for me, it is sometimes easy to hear the detracting comments and not hear the favorable ones. I would advise anyone pursuing a career in science to try to listen to both, but not to attach too much of your confidence to either."

And to do this, Cerreta still relies on the professional network that she has built over the years. "Mentors, colleagues, and friends help put these issues into perspective," she said. 


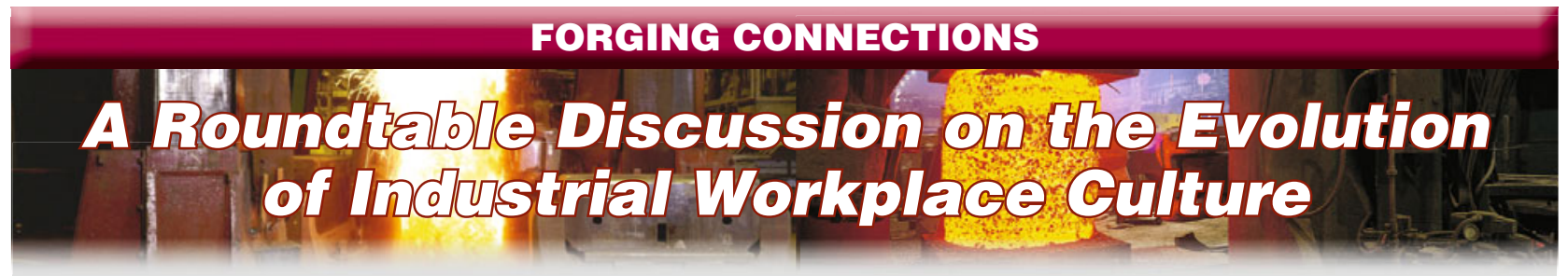

When TIMET started producing titanium in 1950, the thought of a female engineer directing operations on the floor was almost beyond comprehension. With that barrier broken a few decades ago, women have gradually assumed key roles throughout the company's research and production process. JOM interviewed a small group of these individuals, each representing different facets of TIMET's operations and all at different stages of their careers. The roundtable included Eliana Fu, Research and Development Services Engineer; Monica J. Kuny, Chief Metallurgist; Eileen Lloyd, Technical Manager; Louise Ramsden-Hare, Product Metallurgist; Taffi Truax, Quality Assurance Engineer; and Jessica Yeager, Nondestructive Testing Specialist. (For background information on these individuals, read the "Meet the TIMET Roundtable" sidebar article.)

While the topic focused on diversification of the materials science and engineering workforce, it was also clear that gender was not the most important bond shared by these individuals. "We are professionals working together to do a job," stated Fu, the discussion organizer, making a point that as women have become more commonplace in the industrial setting at TIMET, the mental qualifier of "female" preceding "scientist" or "engineer" has faded away as well.



JOM: You have clearly built a strong, supportive network with each other, even though you generally work in different locations and departments. How did this develop?

Fu: Historically, TIMET was a small, independent company that was very interlinked across locations. We interface with each other almost all the time, particularly since some of the women in this discussion are involved in some high profile projects. It's not like we sought each other out- ' $\mathrm{Oh}$, there's another woman. I must talk to her.'

Kuny: This is the fourth place that I've worked, and in some of those locations, I was the only woman. There were no other women to seek out, at least in my function. At TIMET, I feel, because we are all working on the same base group of materials, we interact with each other because of the job functions we have.

JOM: How is the dynamic different than when you were the only woman?

Kuny: That wasn't really a factor for me. You learn to work in an all-male environment, and become used to it. I didn't even think about gender. To me, interacting with so many other women in the sciences at TIMET was actually a big adjustment.

Lloyd: When I joined IMI Titanium Ltd., I was the only female metallurgist at the plant. And, it was very difficult to get a job in industry as a woman back then. It took me a year to find a job after I graduated, because I don't think industry was prepared for women engineers. When I was applying for a job at a steelworks, the man interviewing me told me, 'You won't be sitting in a comfortable office being part of the wallpaper. You'll have to get your hands dirty.' And I thought, 'How often do you get your hands dirty on the shop floor?'

JOM: Have you seen a change in the work culture since then?

Lloyd: It's a change that has occurred as time has gone on, I think since there are generally more women in engineering. Workplace attitudes have had to adjust because of that. And, as women have proved themselves in key roles, and gained a higher profile and wider recognition, it was difficult not to start listening and taking notice of us.

Fu: I think that "old school" mentality still exists somewhat today. At a previous company where I worked, my manager made an offhand remark that he would never hire a woman as a plant metallurgist because he was afraid she would leave to have a baby. And, I thought, 'Great. I have no future with this company.' I don't register that at all with TIMET, though. We don't stop and think, 'There's a woman engineer.' It's just a person doing a job.

Yeager: I've been out of college for five years and have not really experienced any derogatory issues. My biggest problem is that people seem to want to protect you, like they're not sure you can handle a situation. Even when I interviewed here, everyone warned me several times about the 'industrial environment' and asked me if I was prepared for that.

JOM: Do you think that's because you are a woman, or because of your youth? 
Yeager: I think it's primarily because I'm young. All the comments I've ever heard like that have always been presented as, 'I've been working at this mill as long as you've been alive.'

Fu: I hear that all time directed at young people who work in my department. So, it's not just you. It's young people in general.

Truax: When I worked in plastics, I really had to prove myself with the men on the floor. They were very traditional-All their wives stayed home and raised the families. Then, here comes this young woman who tells them what they can and can't make. It was a bit of a challenge, but I found that once I proved myself and they saw that I knew what I was talking about, then everything was $\mathrm{OK}$.

Lloyd: It's hard for men, who have been working a job for 50 years, to suddenly be told how to do something by someone who is a lot younger. I had that in my first year. But all you have to do is build up the rapport and show you are willing to learn from them.

Kuny: You have to respect their knowledge before giving your opinion, based on your knowledge. It's not a gender issue-It's that way across the board.

JOM: Have you ever felt that you had to behave differently because you were different from most of the people that worked with you?

Kuny: I always believe I've acted like myself, although I always felt that I had to prove that I could do better than anyone around me. You have to have a tough skin. You can't let people get to you because you are different.

Ramsden-Hare: One of the biggest compliments I've ever had was when one of my colleagues said I was 'one of the boys.' It didn't mean that I acted like a man, but rather that they saw me as their equal. But, I also have to say that I've never felt penalized or different for being a female in engineering, both in the workplace and at university. Nor, do I feel like I've got to prove more than anyone else.

Lloyd: It's not about being manly. It's a bit of a mix and a balance and showing that you have a 'can do' attitude.

Yeager: In the beginning, I felt I wasn't acting the way I normally would and eventually realized that this was not effective. I was hampering myself by trying to fit in and was not helping anybody. You need to say things that are natural for you, ask questions that are natural for you, and suggest ideas that are natural to you.

Lloyd: I think you also need to be prepared to make tough decisions, and take on responsibilities. Difficult times give you an opportunity to show your strength and build character.

Truax: I agree. When you make a mistake, take responsibility and move forward. And, when you feel you've made the right decision, don't bend to external pressures and start secondguessing yourself. But, be ready to have a respectful discussion.

JOM: What do you think needs to be done to keep the momentum going to increase diversity in the engineering workforce?

Lloyd: From my perspective, it's getting into the schools early and sowing the seeds at a young age. Young people really don't realize the opportunities that are out there. I've done a few presentations at a local primary school, with children nine or 10 years old. And, their eyes light up when they see something that's a little commonplace to us, like different metal pieces. When you show how to apply what they are learning in class to a career, it's opening a door to them.

Kuny: I agree that we need to start younger. I did a program with seventh grade girls and what they liked the best was a corrosion study I did with pineapple juice and salt water. We would experiment with different materials and make connections with why, for instance, your car would rust in the winter from road salt. If you get them young and show them how to apply what they learn to real life, that will stir their interest.

Ramsden-Hare: I also think that there needs to be more inspiration from a school level, and probably at college, too. There are so many engineering disciplines to choose from, but most people have no idea of what is out there because there is more focus on the basic sciences at a school level and not what they can lead to. A misconception I faced myself in school and college was that engineers were scruffy grease monkeys, and that industry is such a dirty place, so why would any girl want to work in a place like that?

Yeager: That's a really good point. I felt very well prepared for college academically, but I had no idea what kind of career choice to make. There was no application of what you do with a physics, math, or chemistry background. I took these classes because they were available and did well in them, but what do I do with that knowledge? I knew nothing about engineering until I went to a career day at the University of Pittsburgh.

Lloyd: I think, in general, it's not well understood what engineers do. I was nominated once for Swansea Bay Woman of the Year and made it to the finals, and I was the only woman in engineering who was nominated. It was clear that the person who interviewed me during the award selection process had no idea of the field that I'm in, the

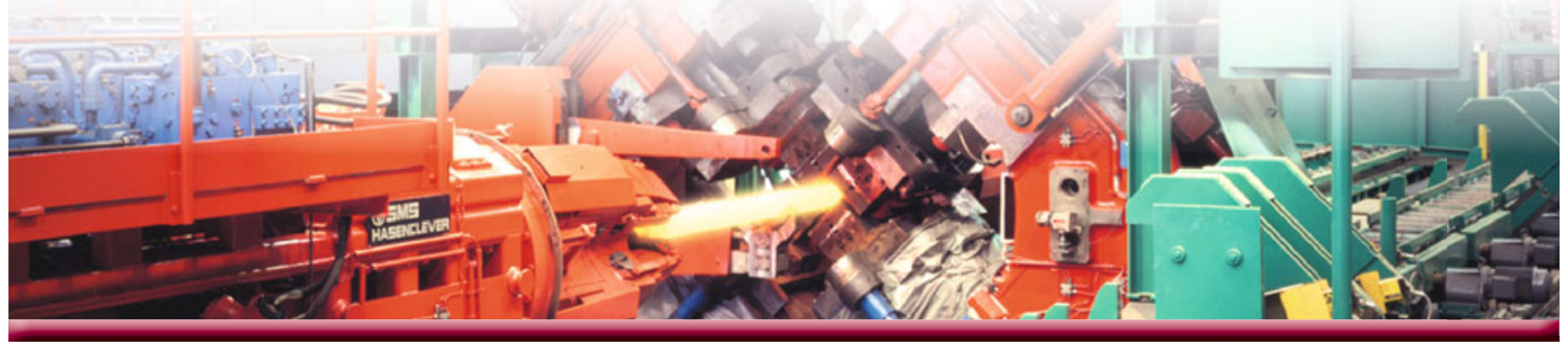


types of decisions I make, and the impact that I can have on whether a material can be released for aerospace applications or not.

Yeager: Many of my friends in school wanted to create and be creative in positions, and not be part of a 'big machine.' I was actually afraid that would happen to me in engineering - that I would not be able to contribute to society. But, what people need to realize is that there are places in engineering where you can make a difference in the world in big ways.

JOM: We've talked about recruitment, but there has also been a num- ber of studies done about attritionWomen leaving engineering and not returning.

Ramsden-Hare: If you do take a break from engineering, it can be difficult to get back in. When I graduated from university, I didn't do anything engineering-related for two years. It was so hard when I tried to return. I had experience in labs as an undergraduate, but no one wanted to hear about that. I went to school for my master's degree because that was the only way I could get back.

JOM: What do you think could have helped your transition?

Ramsden-Hare: It would help if com- panies would recognize that some people would be happy to work for little or no pay just to get the experience so that they can re-enter the workforce.

JOM: What role have mentors played in your career development?

Yeager: I haven't had a formal one. When I was in training for my Level III certification, the current Level III was my mentor because what he did was not really documented. We are completely different people-He's in his $60 \mathrm{~s}$ and has worked in mills all of his life and I'm 28 and this is my first job. But, from the perspective of how do you work in this environment and
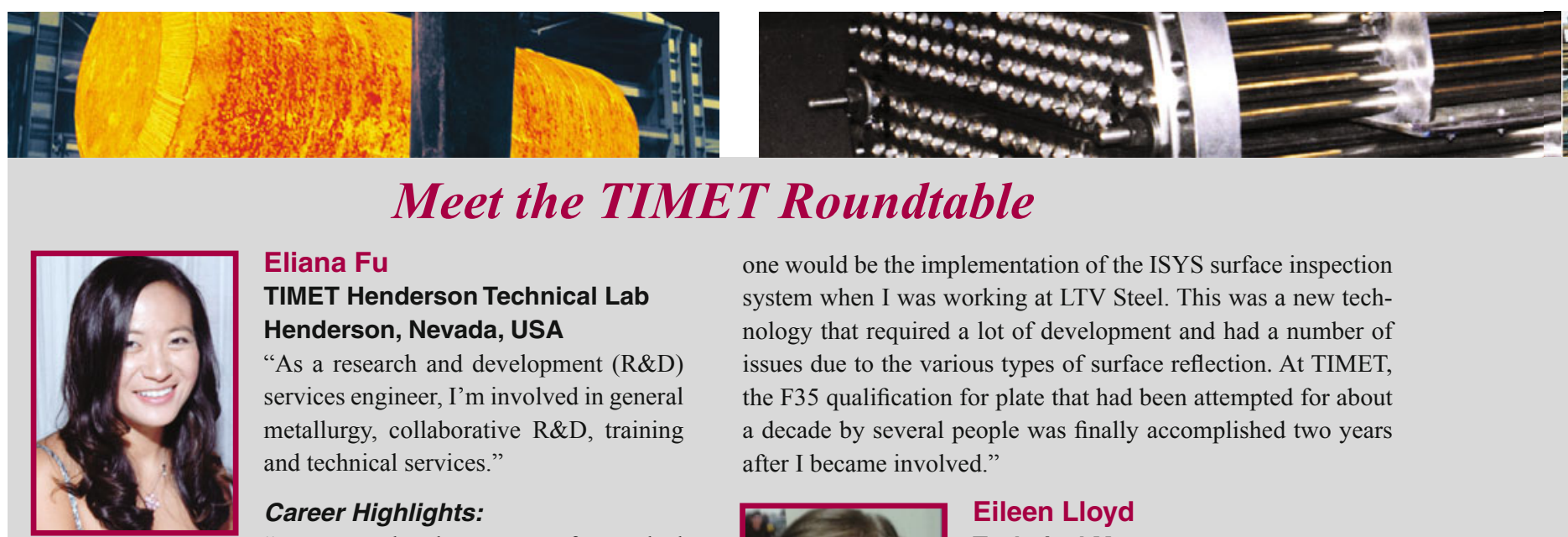

\section{Meet the TIMET Roundtable}

progression. Going in career has been more of a gradual scholars and engineers and having complete confidence in what I am doing and saying is its biggest reward."

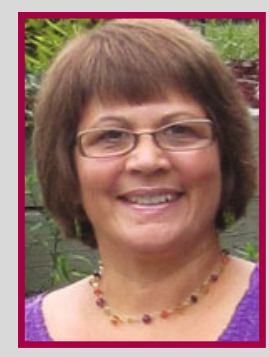

\section{Monica J. Kuny Chief Metallurgist TIMET Sheet and Plate Products Toronto, Ohio, USA}

"I'm involved with the finishing manufacturing of titanium hot rolled sheet and plate products. I am responsible for the material's manufacturing route to meet customer specifications, along with material qualifications and new alloy development, in conjunction with research. In addition, I have the quality and training responsibility for the entire department. With the product metallurgists who report to me, we also develop lower cost routes of manufacture and work to solve quality issues."

\section{Career Highlights:}

"My passion is working with production and with the people in manufacturing. I have been fortunate to maintain a job with at least some ties to floor production. As for specific milestones, one would be the implementation of the ISYS surface inspection system when I was working at LTV Steel. This was a new technology that required a lot of development and had a number of issues due to the various types of surface reflection. At TIMET, the F35 qualification for plate that had been attempted for about a decade by several people was finally accomplished two years after I became involved."

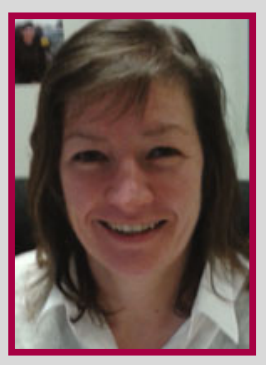

\section{Eileen Lloyd Technical Manager TIMET UK Limited Waunarlwydd, Swansea, Wales}

"I manage the team that ensures compliance throughout the whole process. This encompasses contract review, process control during manufacture, control of non-conforming material, process and new product development, approval of changes and new products equipment, hosting customer audits, implementing actions to ensure continued customer approval of process routes and maintain accreditations, testing and certification of material, sub-contractor approval, and customer interaction."

\section{Career Highlights:}

"I was one of the first female metallurgists to be taken on by IMI Titanium Ltd. (acquired by TIMET in 1996) and I have progressed through the company to become, I believe, the first female technical manager for TIMET UK Ltd. I have seen many changes in my career, as my original company has been taken over twice. I have enjoyed working closely with Rolls Royce and Pratt \& Whitney on new products. Seeing the new engines fly is very satisfying, knowing that my team and I have had a part to play in their development." 
address problems, I've learned more from him than anyone else.

Truax: I had a great mentor when I worked in a research and development company that made batteries. Her nickname was Charlie and she was from Greece. She came to the United States when she was 16 and tested out of high school and had a Ph.D in analytical chemistry by the age of 23 . And, she loved batteries and the chemistry involved. She would forget more in a day than I probably would ever learn. Just to hear her story was very inspiring. And, she was such a solid individual-very accommodating and willing to teach you whatever she knew. That definitely gave me a different outlook on women in the workplace, because up until then, I had only really worked with men. She showed me how strong a woman could be. Meeting and working with her was a turning point in my career.

Fu: What inspires me are the people around me at the moment. For instance, Monica and Eileen show that it doesn't matter what your gender, you're just doing your job. We don't have a structured mentoring program at TIMET, but it happens because others are leading by example and we are able to interact with each other so frequently. But, maybe we should step back and think about issues such as mentoring because those things are important. We are just all too busy getting metal out the door.

Lloyd: You're right. We don't often get an opportunity to recognize each other because we are so busy. But, I think it's good to take time to talk about our accomplishments, because we have indeed contributed to science and society.

JOM thanks TIMET for its assistance and for providing the industrial photographs illustrating this section.
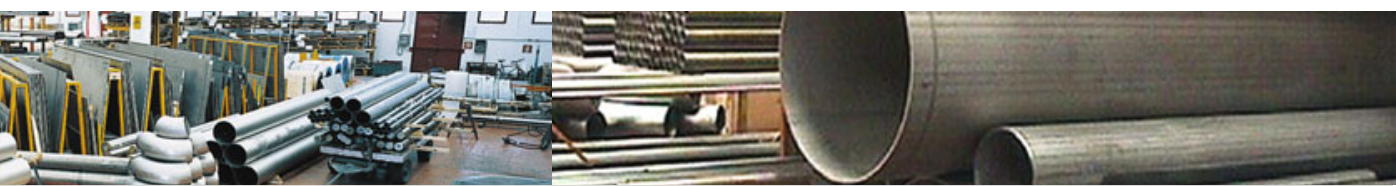

\section{Louise Ramsden-Hare}

Product Metallurgist

TIMET UK Limited

Waunarlwydd, Swansea, Wales

"I have a varied role but am generally responsible for the quality assurance for bar products. I trouble shoot, both on the shop floor and in the laboratory, and am the technical liaison for customers for both approval work and issues. I am also involved in process improvement work and capability testing of new products and processes, and review and update internal procedures and customer documentation."

\section{Career Highlights:}

"Earning my first my degree and then my Ph.D. were quite significant to me, and later on I was quite pleased when I became a Chartered Engineer. Within my role at TIMET, an achievement has been reaching a level of being able to train others. A few years ago, I trained another metallurgist and I'm currently involved in providing annual training and competency assessments in basic metallurgy for some of the laboratory operators."



Taffi Truax

Quality Assurance Engineer TIMET Henderson Quality Department Henderson, Nevada, USA

"I handle all incoming raw materials, conduct audits at our suppliers, and manage the quality system functions at TIMET Henderson according to ISO/AS guidelines."

\section{Career Highlights:}

"I have always worked while in college, but when I went back to college for my second degree in business, I was working 12 hour shifts, 12 days on with two days off. I also had to switch shifts from days to nights every five weeks. I did this for three years. When you work that kind of schedule and go to school full time, you really find out what you are made of. My goal going forward is to be a leader in my industry. Currently I am still learning and there is a lot to learn within my position. Someday, I would like people to come to me with challenging questions and I want to have the experience and knowledge to be able to educate them and lead them in the right direction."

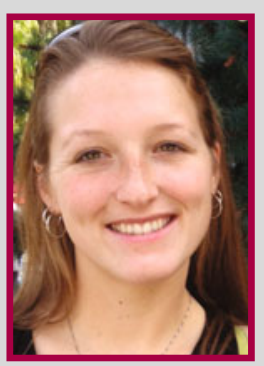

\section{Jessica Yeager Nondestructive Testing (NDT) Specialist, Ultrasonic (UT) Level III TIMET Toronto Toronto, Ohio, USA}

"Five years ago I began at TIMET as a product metallurgist and had the opportunity to work in forged and flat rolled products for nearly three years before applying for and accepting my current position. As an NDT specialist with a Level III ultrasonic certification, it's my responsibility to provide technical guidance for the NDT department and to ensure that we adhere to relevant customer and industry requirements."

\section{Career Highlights:}

"Now that I've achieved my Level III certification, I'm working towards the customer-specific certifications which are required. I'm also pursuing my MBA part-time. Although I am enjoying the course work I'm also looking forward to completing my post-graduate degree." 


\section{Science and Diversity: Be like Twitter, Not Facebook}

\section{By Ainissa G. Ramirez}



When it comes to science we should be more like Twitter and less like Facebook. Twitter is a way to connect with strangers with the same interests; by connecting to like-minded people you can enhance your learning and be exposed to new things. Facebook, on the other hand, is a closed network of private connections. Here, shared ideas grow stagnant and banal, like

kid's birthdays and such. Scientists interact with each other and hire each other like Facebook, but we should consider being more open like Twitter.

A key tenet in science is the exchange and refinement of ideas. Consider the notion of creativity. There are two schools of thought: divergent thinking and Janusian thinking. Divergent thinking is the creation of new ideas by having lots of them. Thomas Edison was a master divergent thinker. Janusian thinking, which gets its name from the Roman god of opposites, is the linking of ideas that come from very different domains. Henri Poincare, the famous mathematician, was a disciple of this kind of thinking.

Both of these types of creativity are based on having a rich source of ideas to generate great ideas. If you agree that science needs lots of ideas to move forward, then you can understand the importance of diversity in science. Every human has a wide range of experiences that colors the way they think and create. If we hire people with similar backgrounds, we are limiting ourselves with a box of 8 crayons, instead of a box of 64. There is a greater chance of a breakthrough when ideas come from a wide and varied pool, in contrast to a homogeneous one.

Diversity increases the richness and brilliance of ideas. As you might know, the Massachusetts Institute of Technology (MIT) was once an all-male institution. Over the years, the "quality" of students, as told to me anecdotally, was less and less brilliant over time. When MIT admitted women and accessed the other $50 \%$ of the population, the quality of the students surged significantly. A similar case can be made for including under-represented groups in science.

\section{The Culture of Science}

Science requires a perseverance that tests the mettle of any person. My life experience as an African American has developed my perseverance, since no one expected me to succeed in science and I wanted to prove them wrong. If I were staffing a laboratory today, I would want more people who persevere. Perseverance is a key ingredient in science: Marie Curie distilled tons of ore to get her radium. Daniel Shechtman had formidable detractors against his quasicrystals. Both got Nobel Prizes. Perseverance won.

When it comes to African Americans in the sciences, we stand on the shoulders of giants who excelled with less than ideal opportunities. George Washington Carver, a former slave, cultivated the peanut, which is a billion dollar industry today. The Super Soaker, an extremely popular toy water gun, was invented in the bathtub of nuclear engineer, Lonnie Johnson. And, my favorite black scientist, Percy Julian, synthesized steroids, cortisone, and the birth control pill all while working at a paint company, Glidden. Imagine what he and others would have had the potential to do if they had operated without such constraints. Society loses when we don't let everyone participate fully in the sciences.

To advance science, we need a paradigm shift, as Thomas Kuhn describes in The Structure of Scientific Revolutions (University of Chicago Press, 1962). Our paradigm shift lies in increasing the diversity in science. To boldly go where humankind has not gone before, we need all hands on deck of every stripe and from every corner of the world. This is why science needs to be more of an open exchange of ideas from vastly different people, like Twitter. Our future deserves better than continuing to act with homogeneity and banality like Facebook. Let's be bold and make the switch.

Ainissa Ramirez, formerly an associate professor of mechanical engineering and materials science at Yale University, has written many scientific articles and the book Save Our Science, based on her TED talk. She is writing a book on the science of football with Allen St. John titled Newton's Football (Random House, available 24 September 2013).

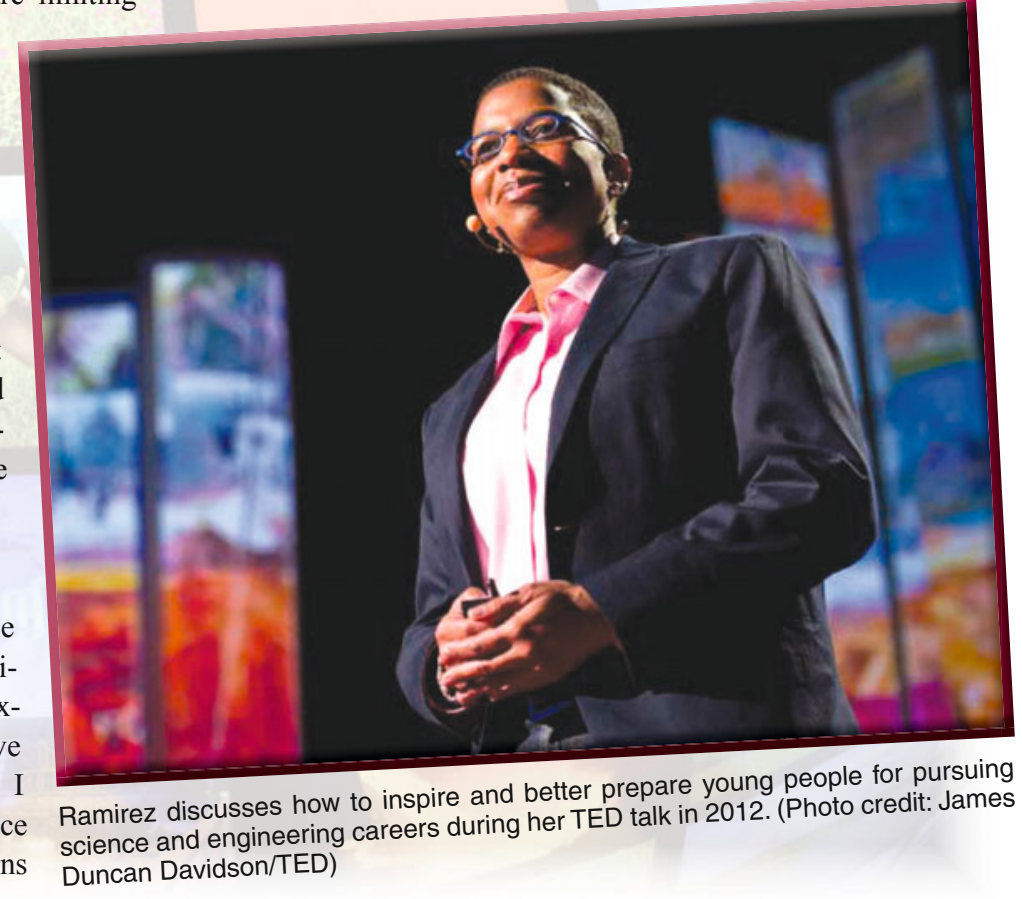

